\title{
Tribological Analysis of Hydrophobic Thin Film with Antimicrobial Properties
}

\author{
Elizabeth E. DeFusco \\ West Virginia University
}

Follow this and additional works at: https://researchrepository.wvu.edu/etd

\section{Recommended Citation}

DeFusco, Elizabeth E., "Tribological Analysis of Hydrophobic Thin Film with Antimicrobial Properties" (2012). Graduate Theses, Dissertations, and Problem Reports. 3325.

https://researchrepository.wvu.edu/etd/3325

This Thesis is protected by copyright and/or related rights. It has been brought to you by the The Research Repository @ WVU with permission from the rights-holder(s). You are free to use this Thesis in any way that is permitted by the copyright and related rights legislation that applies to your use. For other uses you must obtain permission from the rights-holder(s) directly, unless additional rights are indicated by a Creative Commons license in the record and/ or on the work itself. This Thesis has been accepted for inclusion in WVU Graduate Theses, Dissertations, and Problem Reports collection by an authorized administrator of The Research Repository @ WVU. For more information, please contact researchrepository@mail.wvu.edu. 
Tribological Analysis of Hydrophobic Thin Film with Antimicrobial Properties

\section{Elizabeth E. DeFusco}

Thesis submitted to the

Benjamin M. Statler College of Engineering and Mineral Resources at West Virginia University

in partial fulfillment of the requirements

for the degree of

Master of Science

in

Mechanical Engineering

Darran R. Cairns, Ph.D., Chair

Konstantinos A. Sierros, Ph.D.

Xueyan Song, Ph.D.

Department of Mechanical and Aerospace Engineering

Morgantown, West Virginia

2012

Keywords: Sol gel, Hydrophobic, Tribology, Antimicrobial

Copyright 2012 Elizabeth E. DeFusco 


\begin{abstract}
Tribological Analysis of Hydrophobic Thin Film with Antimicrobial Propeties
\end{abstract}

\title{
Elizabeth E. DeFusco
}

Silica based sol gel thin films have become a very popular area of research due to their high degree of variability and ease of manufacturing. They are commonly used as coatings for many applications in the consumer electronics and automotive industries. Some common properties in these thin films include optical transparency, wear resistance, antimicrobial, hydrophobic, electromagnetic, etc.

The coating produced in this research has been tailored to meet three key functions; durability, hydrophobicity, and anti-microbial properties. This coating is created through a three-step sol gel reaction mechanism. The starting chemical, tetraethoxysilane (TEOS), yields the final product of a silicon dioxide matrix. During the reaction process, other functional chemicals, including quarternary ammonium salts to increase antimicrobial properties, are incorporated to achieve the desired properties. The sol is then dip coated on to a substrate, glass microscope slide, and then used for further testing.

Testing of these coatings included contact angle analysis to measure the degree of hydrophobicity, reciprocating wear to test the durability of the coating, stylus profilometery to measure the total coating thickness and coating loss as a function of wear, and cell culture studies to determine the efficacy of the antimicrobial agent. 


\section{Acknowledgments}

I would like to thank Dr. Darran Cairns for the opportunity to work with his lab group for the past two years. It has been a great experience and I have learned an immense amount of information over this time period. I would also like to thank him for introducing me to the education side of engineering. Through these experiences I discovered my own desire to teach engineering across all levels. This is extremely important to me as I start the next chapter in my career.

A big "thank you" is also well deserved for my committee members, Dr. Xueyan Song and Dr. Kostas Sierros. I have absorbed much information from all the courses that I have taken during my studies.

Of course, I have to thank all the members, past and present, of the lab group: Nick Morris, Aaron Kessman, Derrick Banerjee, Ed Chambers, Sean Cronin, Andrew Hoover, Phil McElfresh, and Teddy Bejitual. Everyone has been a great friend and coworker.

My friends and family have been a great source of support throughout all of my schooling.

Lastly, to Sean: you have been my biggest believer and have always pushed me to do great things. I cannot express how grateful I am for all of your love and support. 


\section{Table of Contents}

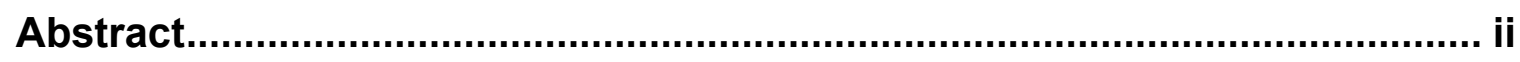

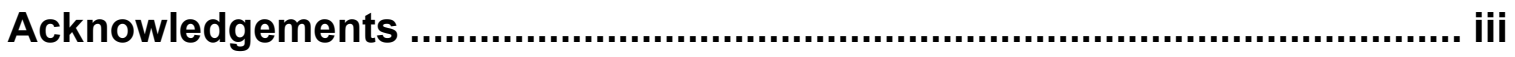

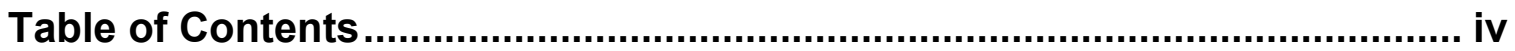

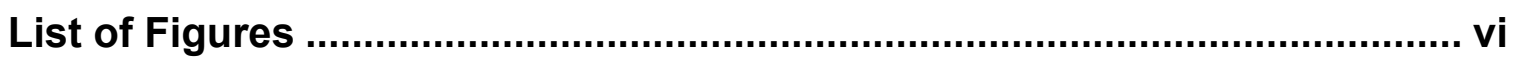

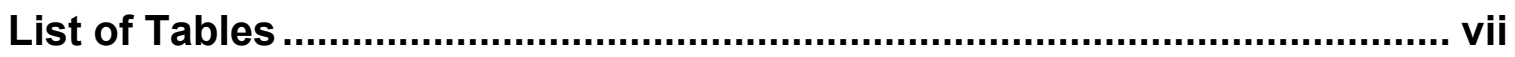

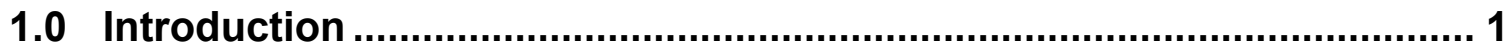

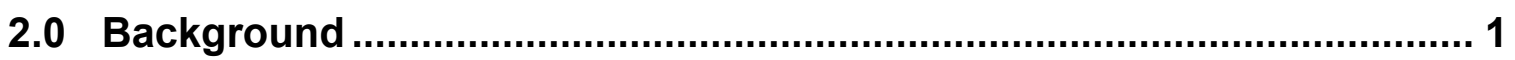

2.1 Thin Films

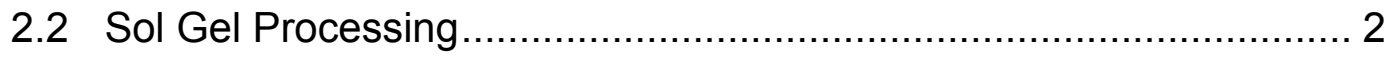

2.3 Substrate Deposition ............................................................... 5

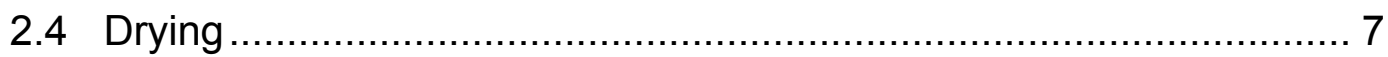

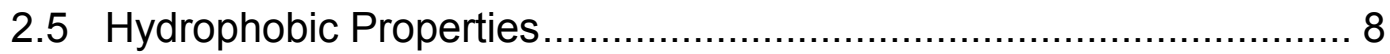

2.5.1 Contact Angle Analysis ................................................ 9

2.6 Antimicrobial Properties .......................................................... 12

2.6.1 Cell Culture Studies ................................................... 14

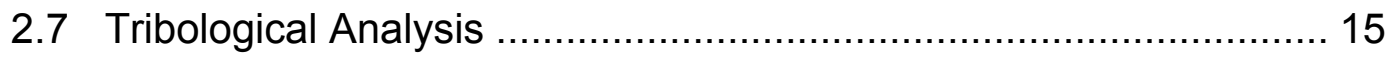

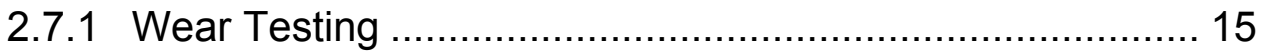

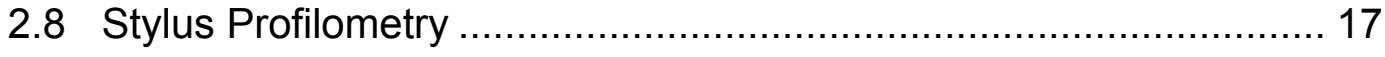

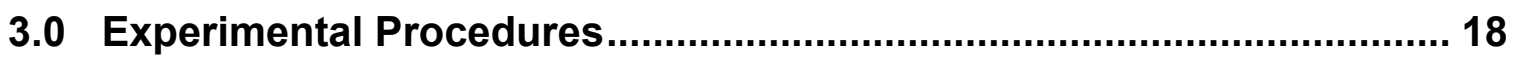

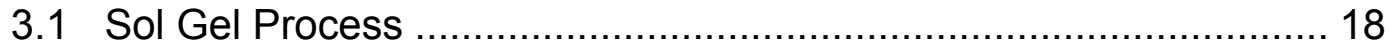

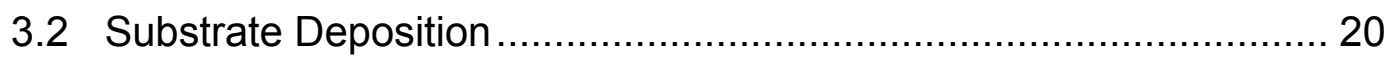

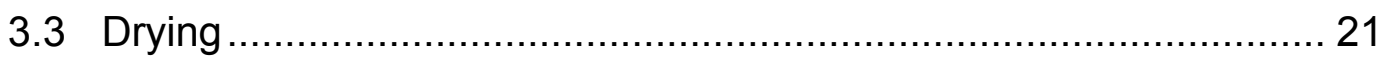




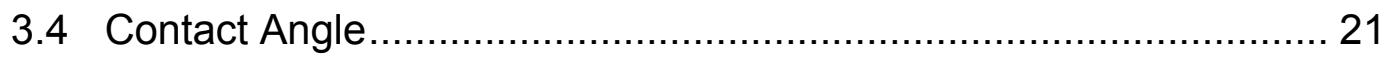

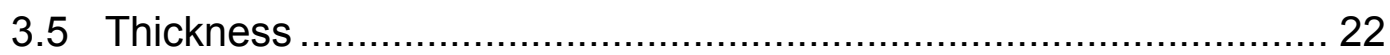

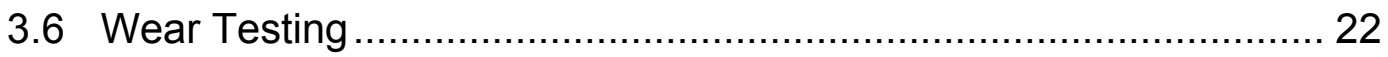

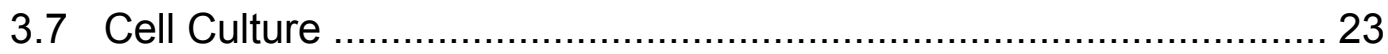

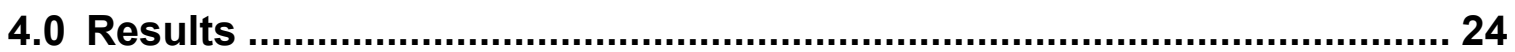

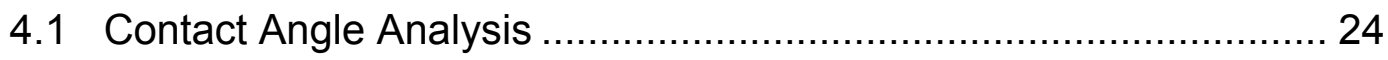

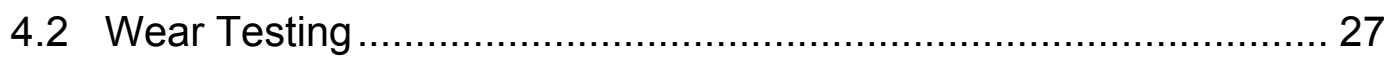

4.3 Cell Culture Studies ........................................................... 28

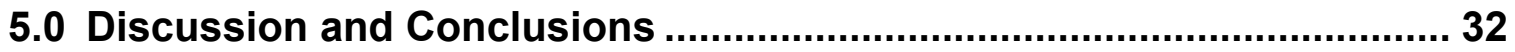

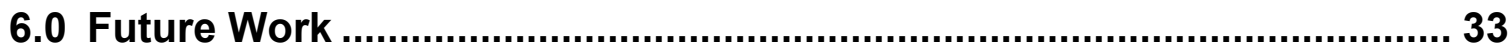

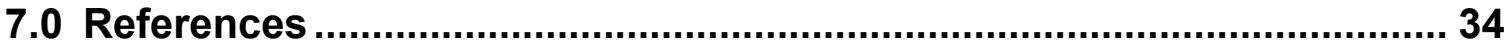

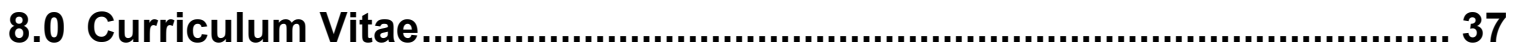




\section{List of Figures}

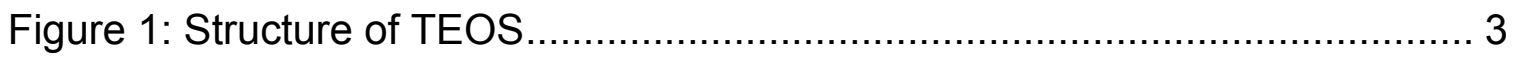

Figure 2: Final products of sol gel process ............................................... 5

Figure 3: Schematic of spin coating process ................................................. 6

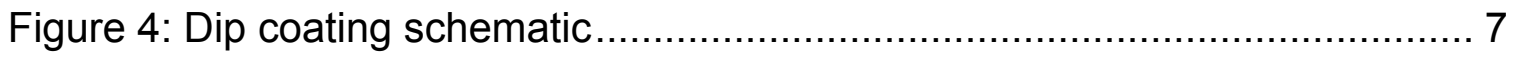

Figure 5: Relative contact angles for hydrophobic and hydrophilic surfaces ....... 9

Figure 6: Example of advancing and receding contact angles by automated

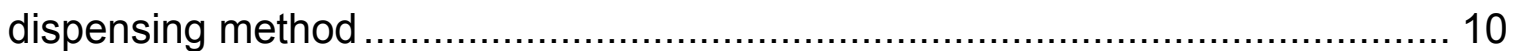

Figure 7: Scanning electron microscope images of lotus leaf structure .............. 11

Figure 8: Wenzel's approach for superhydrophobicity .................................... 12

Figure 9: Cassie's approach for superhydrophobicity .................................... 12

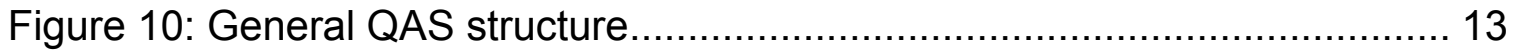

Figure 11: Structure for naturally occurring chitosan .................................... 13

Figure 12: Quarternization process of chitosan .......................................... 14

Figure 13: Schematic for pin-on-ring tribometer........................................... 16

Figure 14: Schematic for pin-on-disk tribometer ........................................... 16

Figure 15: Schematic for four-ball tribometer............................................ 17

Figure 16: General schematic for stylus profilometer...................................... 16

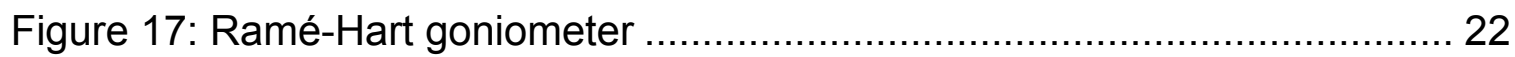

Figure 18: Example of sample contact angle analysis photo ........................... 26

Figure 19: Contact angle as a function of wear................................................ 28

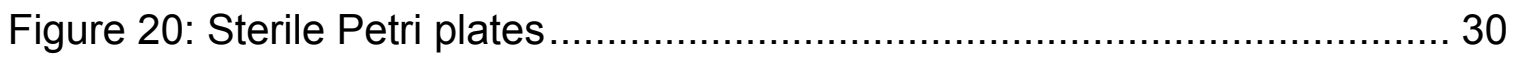

Figure 21: Heated shaker machine used for sample incubation before plating .. 31

Figure 22: Cultured Petri plates ................................................................ 32 


\section{List of Tables}

Table 1: Surface contact angle comparison based on diluent .......................... 27

Table 2: Surface contact angle on samples of same formulation, coated at

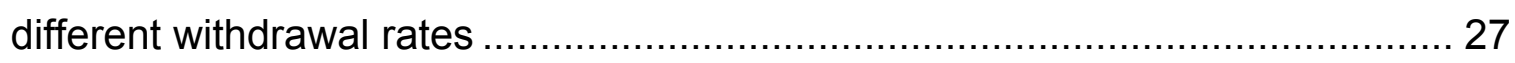

Table 3: Average coating thickness per wear cycle ...................................... 29 


\subsection{INTRODUCTION}

The purpose of this research was to develop a silica based sol gel thin film with three properties: hydrophobic, durable, and antimicrobial. Research in this area is driven by daily life, most importantly consumer electronics. As more and more aspects of our daily lives are centered on electronic devices, the need to keep these devices operating is essential. Thin films are common coatings on touch screen displays, solar panels, and many other surfaces. The three properties of interest are crucial when developing a thin film coating. The hydrophobic properties will make the surface very easy to clean and it will resist water, the durability will make it withstand wear by abrasives, and the antimicrobial properties will prevent bacteria growth.

Sol gel processing was used to create these films. This is a very common processing technique used for thin films. This technique is easily performed in a laboratory as a one-pot co-condensation reaction. The addition of specific functional chemicals is used to tailor the properties of the coating. When creating these coatings, one variable was changed at a time. This allowed a proper analysis of the effects of each change.

The thin films were then coated onto glass substrates for further testing. Each

property has its own unique testing procedure. Hydrophobicity was tested by contact angle analysis, durability was tested with the use of tribometer to measure wear, and antimicrobial properties were evaluated by cell culture studies. The coatings were made so that all three properties co-existed.

\subsection{BACKGROUND}

\subsection{Thin Films}

Thin films have been a topic of research in the materials science and engineering 
world for many years. One particular area of interest in thin film research is the creation of hybrid organic-inorganics. These thin films are types of coating that possess unique qualities and are typically on the nanometer scale of thickness. These coatings are desirable because each group has its own unique contributions. Organics have electronic properties, photoconductivity, structural flexibility and ease of processing. The inorganics offer magnetic and dielectric properties, carrier mobility, and thermal and mechanical stability (1). Therefore these films will require special techniques to analyze their properties.

The scale of a thin film can make it challenging to study their properties. This is because thin films are on the nanometer to micrometer range for thickness. To study these films further, they need to be coated onto a substrate. One advantage of thin films is, even when coated on to a substrate, they do not affect any of the properties of the substrate. Thin films merely exhibit their own properties independently. This makes thin films very useful in many applications in chemical processing plants, electronics coatings, biosensors, automotive industry applications, and many other areas (2-4).

As mentioned previously, the main focus of this research is in silica based thin films. These have been a very popular research area for many years. Silica thin films typically have hydrophobic and optically transparent properties. The durability of these coatings is also very variable and an important area of focus.

\subsection{Sol Gel Processing}

Silica sol gel research can be traced back as far as the 1800s to the works of Graham and Ebelman (5). Sol gel is a common processing technique among chemists, chemical engineers, material scientists, and many others. A sol gel process is referred to as a process in which a colloidal suspension, or "sol" undergoes a transition, through a set of reactions, into a gel phase. It is a 
desirable technique because it can be preformed at ambient pressure and temperature, and with mild chemicals (6). The process also has a high degree of variation, as there are many factors that can be manipulated to achieve the desired product. This is most commonly used to create a thin film system that can possess a multitude of functions, and will be discussed later.

The sol gel process is centered on inorganic polymerization reactions to prepare final products such as ceramics and glasses (7). One particular sol gel process of interest is that of tetraethoxysilane (TEOS). This results in a final product of silicon dioxide $\left(\mathrm{SiO}_{2}\right)$. A common starting alkoxysilane is tetraethoxysilane (TEOS), shown in Figure 1. TEOS is used because it is simple to synthesize

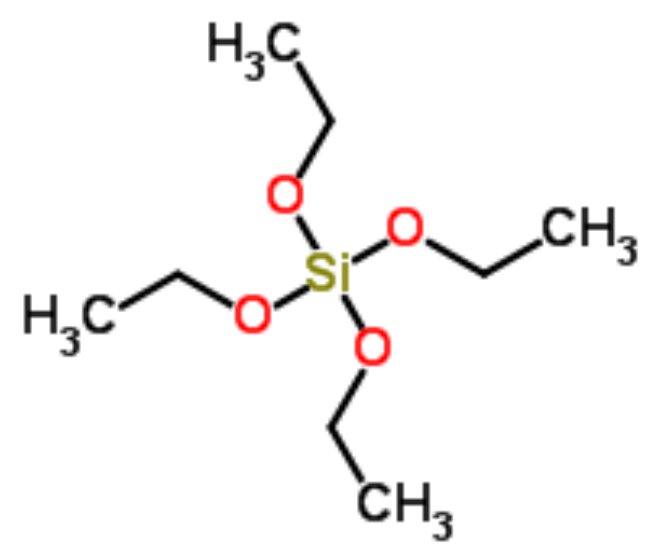

Figure 1: Structure of TEOS

This process is a three-step reaction mechanism that includes hydrolysis, water condensation, and alcohol condensation. These three steps are shown in Equations 1-3, respectively.

$$
\begin{aligned}
& \equiv \mathrm{Si}-\mathrm{OR}+\mathrm{H}_{2} \mathrm{O} \leftrightarrow \quad \equiv \mathrm{Si}-\mathrm{OH}+\mathrm{R}-\mathrm{OH} \\
& 2 \equiv \mathrm{Si}-\mathrm{OH} \leftrightarrow \quad \equiv \mathrm{Si}-\mathrm{O}-\mathrm{Si} \equiv+\mathrm{H}_{2} \mathrm{O}
\end{aligned}
$$


$\equiv \mathrm{Si}-\mathrm{OH}+\equiv \mathrm{Si}-\mathrm{OR} \leftrightarrow \equiv \mathrm{Si}-\mathrm{O}-\mathrm{Si} \equiv+\mathrm{R}-\mathrm{OH}$

The first step, hydrolysis, occurs when TEOS is mixed with water. This is done in the presence of a solvent, typically ethanol $(\mathrm{EtOH})$, to make these two substances miscible (8). This step occurs in the presence of an acid catalyst, to occur rapidly and exothermically. This reaction results in the creation of silanols and alcohols.

The second step condenses the water by reacting two silanols to produce a long chain of siloxanes. The third step reacts a silanol with the starting alkoxide to form more of the long chains of siloxanes. Therefore, the second and third steps happen simultaneously. These reactions then leave a solution, called a sol, made up of water, alcohol, and siloxane. The longer the sol is left to react the more chains will be produced. This polymerization process will continue until the sol has reached a gel state, and then eventually solidify. Transferring the sol from the reaction container to a substrate to create a thin film must be done before this state is reached.

There is a period of time when all reactants are added and when the sol reaches a gel state. This is called an aging period. Aging is required to ensure that the sol gel is mixed completely and homogeneously, this involves the cross-linking of polymers to continue (6). As the sol gel ages, the properties can continue to change because of the reactions still taking place. Therefore samples of different ages are taken and properties are evaluated. The final stage of aging is the gelation, this is when the sol has reached a final gelled state and will no longer flow as a liquid. The aging time is crucial to ensure that the sol is reacted enough before transferring to a substrate. For example, if optically transparency is a desired property, a long aging time is not desirable. The sol will start to coagulate as the gel state is approached, and this will hinder the transparent properties of the sol as it is coated on to a substrate. 
Once a sol is ready for processing, there are many options that can be taken. This thesis is focused on thin film production, but sol gels can be used to create fine powders, ceramics, and aerogels (9-13). Figure 2 shows a schematic of the process from initial to final products.

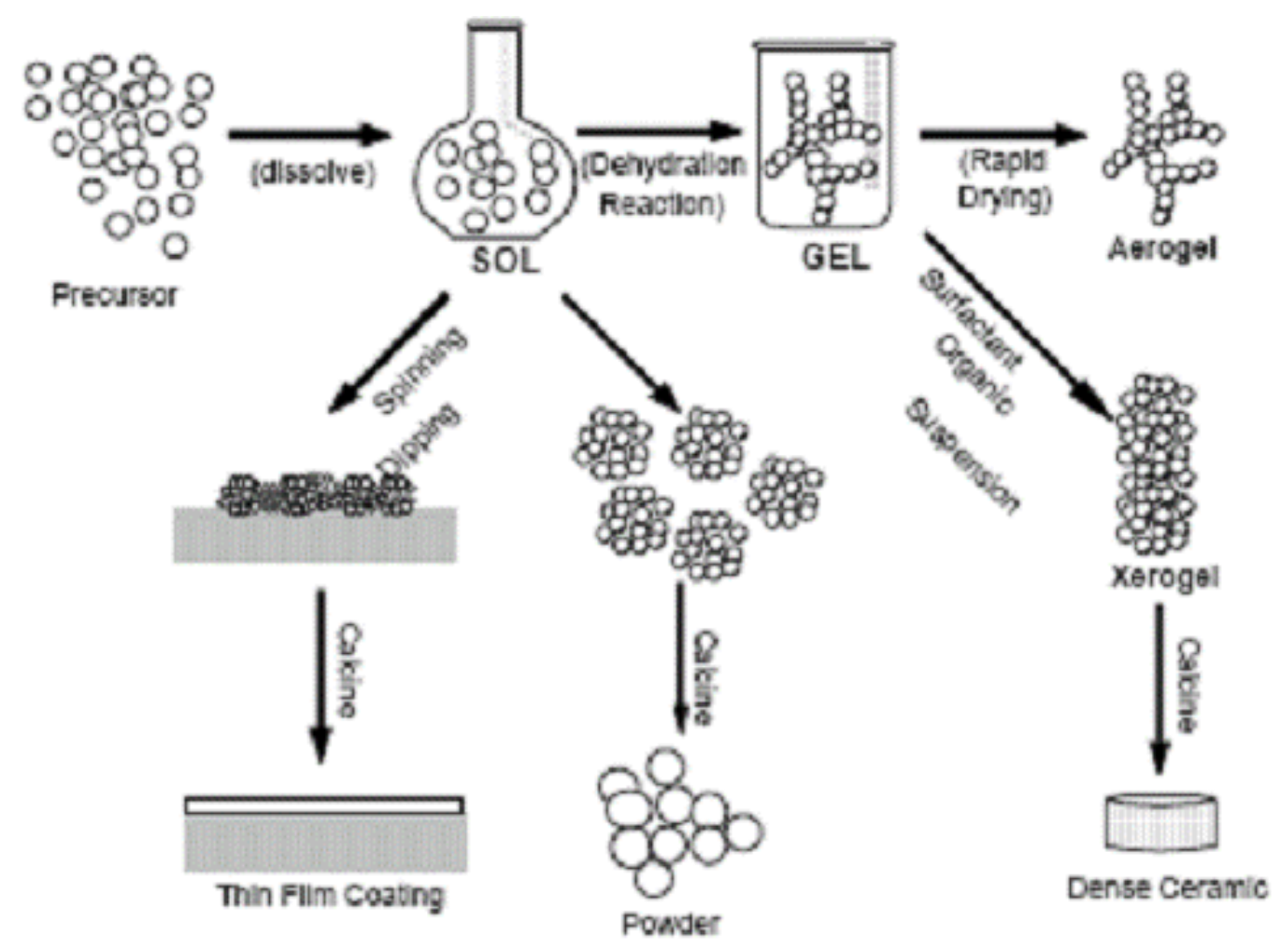

Figure 2: Final products of sol gel process (14)

\subsection{Substrate Deposition}

The unique aspect of sol gel based thin films is that they are processed in liquid state, so they can be coated on to a wide range of substrates and they can be deposited in multiple ways, as they are able to conform to substrate shapes. Substrate deposition techniques include spray coating, dip coating, and spin coating. Spin coating is a procedure where a specified amount of sol is placed on top of the substrate; the substrate is then spun at a specified speed until the coating is evenly dispersed (15). A schematic for spin coating can be seen in Figure 3. 


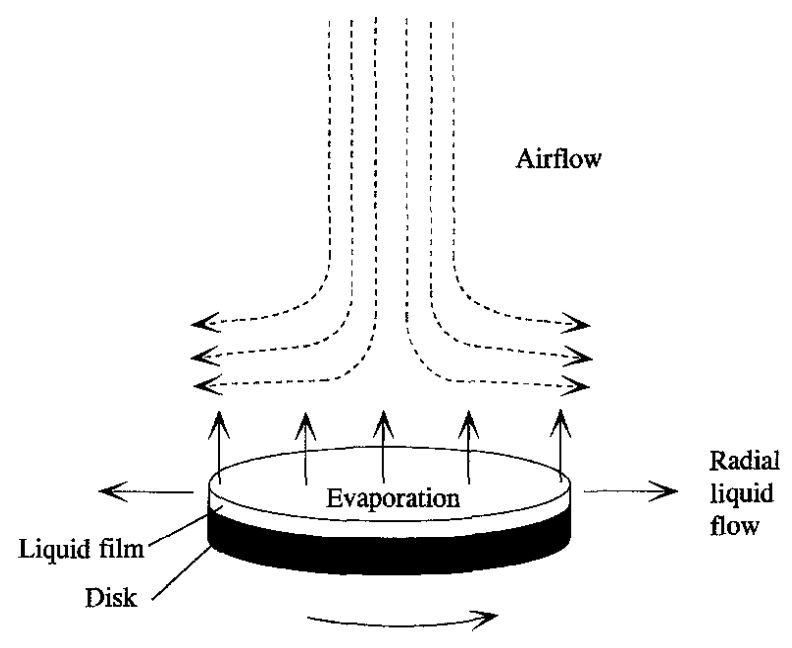

Figure 3: Schematic of spin coating process (15).

Dip coating is an immersion technique where the substrate is immersed in the sol then withdrawn at a constant speed. Dip coating is popular because of its thickness uniformity upon deposition. The manipulation of coating thickness is dependent on the withdrawal speed of the substrate from the sol. The slower the withdrawal speed, the thinner the coating, and vice versa. This effect is due to shedding as the substrate is withdrawn from the solution. Figure 4 shows the different stages that come into effect when dip coating a sol gel (16). 


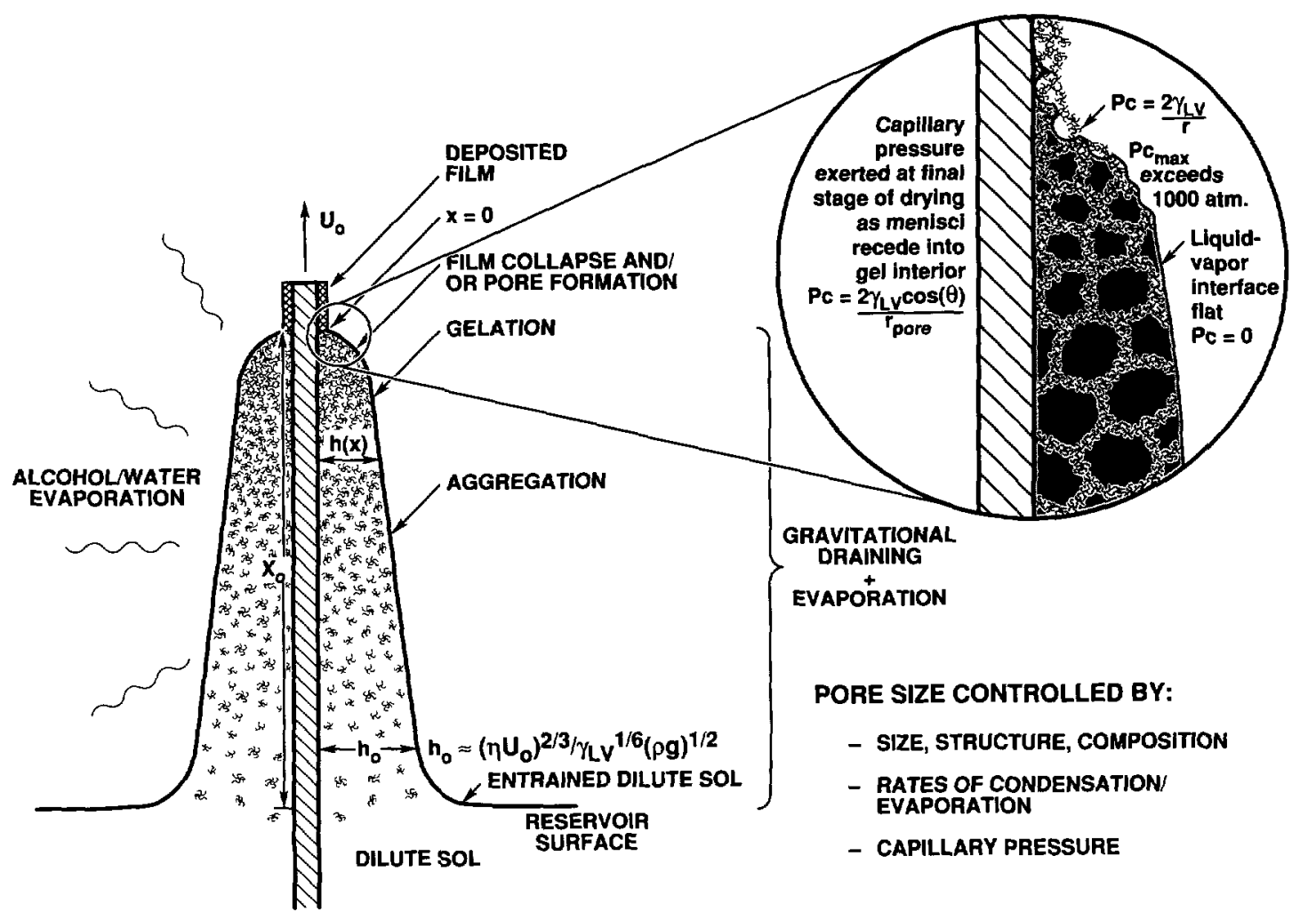

Figure 4: Dip coating schematic (16).

Glass is a common substrate for sol gel because of good adhesion properties between the two. As the glass is withdrawn from the sol, at a constant withdrawal speed, gravity starts to force the bulk of the film back down. As this is occurring, alcohol and water are evaporating from the sol, this causes the rest of the film to concentrate and aggregate close together. This forms a xerogel, a solid that is formed from a gel drying and shrinking. The faster the withdrawal speed, the less time there is for the sol to shed from the surface of the substrate; this produces a thicker coating.

\subsection{Drying}

After the thin film is coated on to a substrate a drying procedure is needed to evaporate any other unwanted products out of the film and solidify the exposed surface. This must be done in a closed and heated environment. The temperature must be raised high enough to burn out any unwanted materials, but 
not so high as to compromise the functionality of the coating. Drying is also used as a final densification of the coating, which increases the hardness (6).

\section{$2.5 \quad$ Hydrophobic Properties}

Once the sol has been coated on to a substrate and dried properly, the function analysis can begin. One key property of silica based sol gels is their inherent hydrophobic properties (5). A hydrophobic, "water-hating", environment is created by the surface as polar molecules are rejected. As mentioned before, as electronic devices are becoming increasingly popular within every aspect of daily life, keeping these devices operating is crucial. Most electronic components are very sensitive to, and can be easily damaged by, water. A hydrophobic, waterhating, environment is desirable to keep these products operating. This can be achieved by encasing the water-sensitive components, but sometimes this may not always be feasible. The next best option is to create a barrier to prevent the water from damaging these components. Hydrophobic coatings are used to create this barrier.

Hydrophobic coatings are also very common to create an "easy clean" surface (17). This is described as such because water, dirt, and oil can be cleaned very easily from the surface and will leave little to no residue.

Hydrophobic properties also depend on the texture of the surface. A very smooth surface is not conducive to a high contact angle. The lack of roughness on the surface will cause a water droplet to lie flat on the surface. A templated rough surface will allow the water droplet to stay as round as possible and sit on top of the surface while maintaining its shape. This is further explained as superhydrophobicity. 


\subsubsection{Contact Angle Analysis}

Hydrophobicity, is measured by placing a drop of water on a surface then measuring the angle between the surface plane and a line tangent to the water drop. This tangent line represents the point where all three phases, solid, liquid, and gas, are present. The surface of the coating is the solid phase, the water droplet is the liquid phase, and the air surrounding both is the gas phase.

Surface tension is used to explain the forces that dictate how a water droplet will orient itself while on a surface. This is shown in Young's equation, Equation 4, and illustrated in Figure 5.

$$
\gamma_{s v}=\gamma_{s l}+\gamma_{l v} \cos \theta_{Y}
$$

where, $\theta_{Y}$ is the contact angle and $\gamma$ is the surface tension of the three interfaces (18).

\section{Hydrophobic Surface}

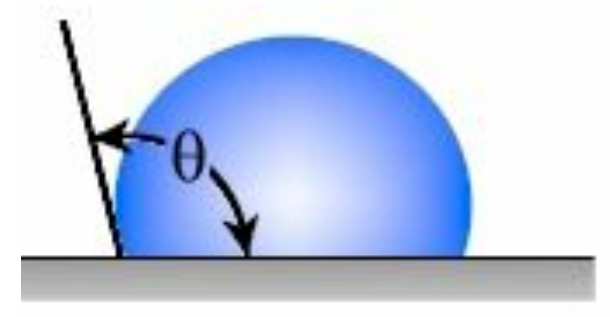

Hydrophilic Surface

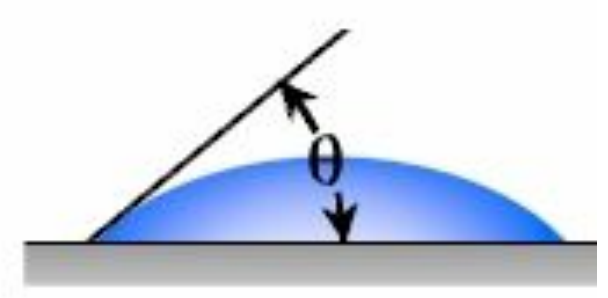

Figure 5: Relative contact angles for hydrophobic and hydrophilic surfaces (19)

A contact angle $>90^{\circ}$ is considered a hydrophobic surface. Static contact angle is the most common method for measuring hydrophobicity of a surface. Although, there are other methods that are used, dynamic, advancing and receding, and sliding contact angles $(20,21)$. These other methods are illustrated in Figure 6. 


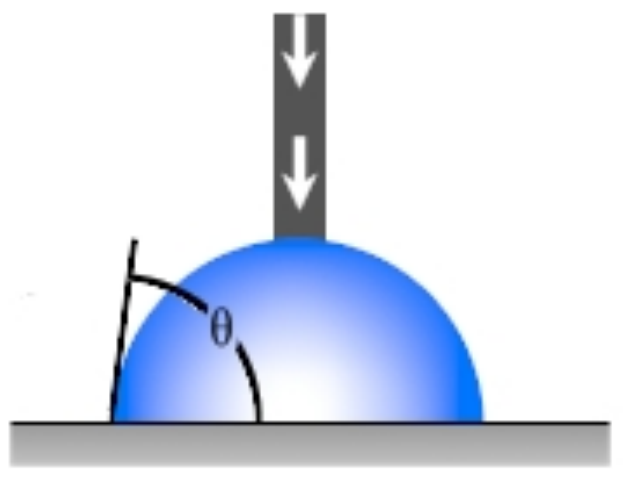

advancing angle

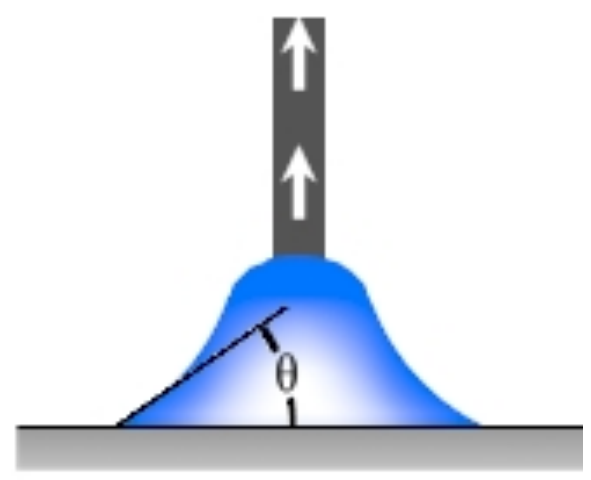

receding angle

Figure 6: Example of advancing and receding contact angles by automated dispensing method (22)

There is also a special case of superhydrophobicity. This is seen as the static contact angle is greater than $150^{\circ}(23)$. This is becoming a more popular research area in biomimetics, as superhydrophobicity is commonly seen on many leaf structures, most famously the lotus leaf; its structure is shown in Figure 7. Replicating this templated microstructure is one common approach to achieve superhydrophobicity. Another approach is through the use of surface modifying agents. These agents are used to replace an $\mathrm{H}$ from an $-\mathrm{OH}$ group with a functional organic (ie, alkyl, aryl). This substitution helps to enhance the hydrophobicity (24). 

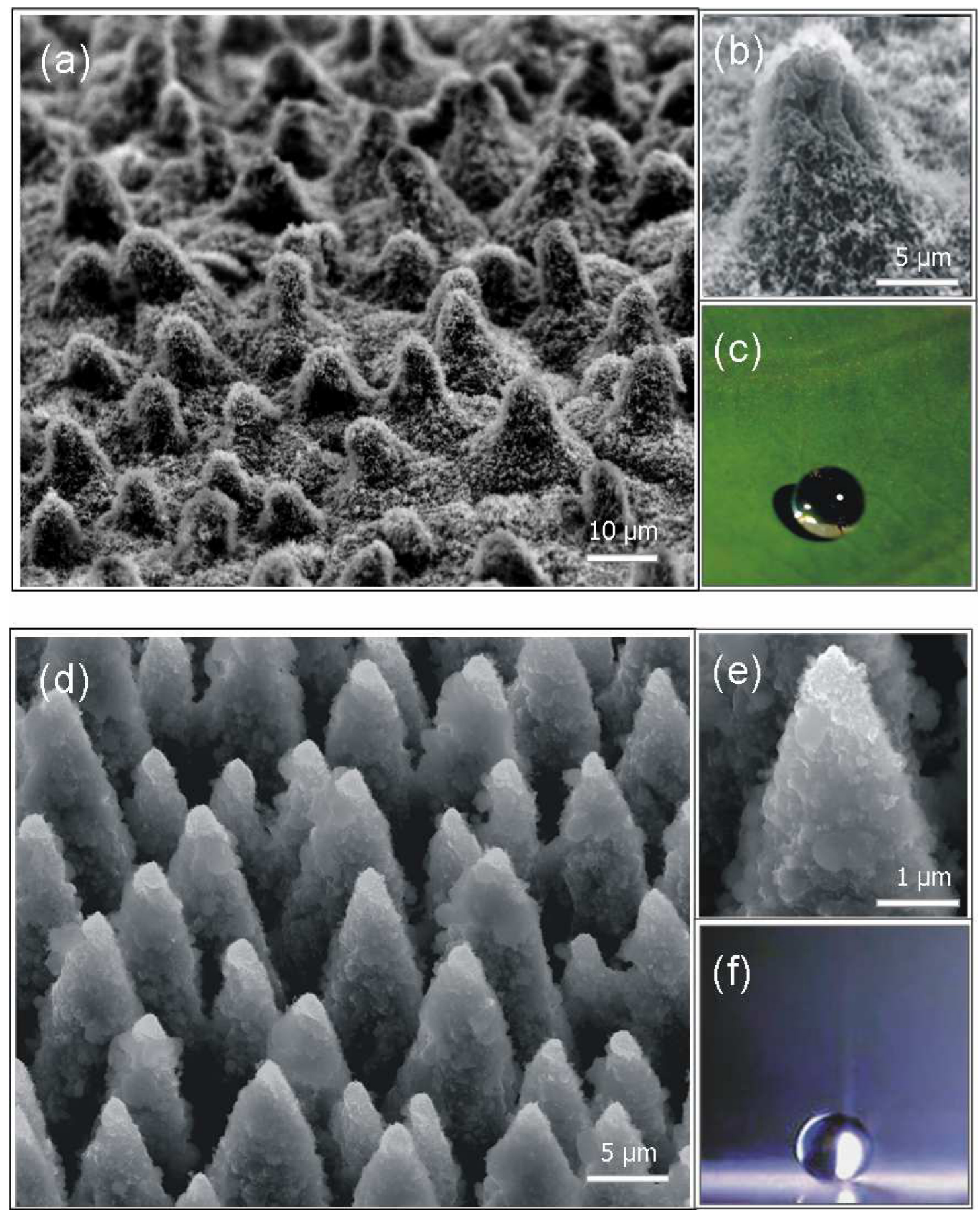

Figure 7: Scanning electron microscope images of lotus leaf structure (25).

Since a surface microstructure is needed to achieve hydrophobicity, so these surface energies do not follow Young's equation because the interface between the liquid and solid is no longer continuous. Superhydrophobic surfaces tend to follow one of two approaches: Cassie or Wenzel (26). 
In Wenzel's approached, it is assumed that the water sits on top of the microstructure, with the voids being filled by vapor pockets. This is illustrated in Figure 8. This will mean that the water will sit across the pieces of the surface that protrude upwards. This causes the water to retain its natural round shape.

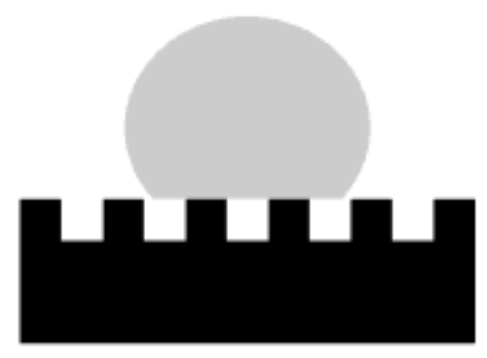

Figure 8: Wenzel's approach for superhydrophobicity

Cassie, on the other hand, states that the water fills in the voids in the microstructure, and is still able to have a high contact angle. This is shown in Figure 9.

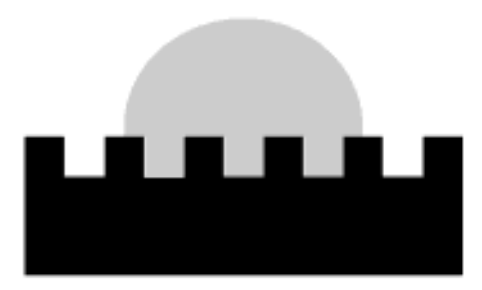

Figure 9: Cassie's approach for superhydrophobicity

\subsection{Antimicrobial Properties}

There are many known chemical groups that have been proven to inherently posess antimicrobial properties. Some of these include copper, zinc, silver, chitosan, ammonium salts, etc (27). Each of these groups has their own advantages and disadvantages. For example, the heavy-metal additives, such as 
zinc, silver, and copper, have negative toxicity effects. One particular group of interest is the quarternary ammonium salts (QAS). The structure of this group is shown in Figure 10.

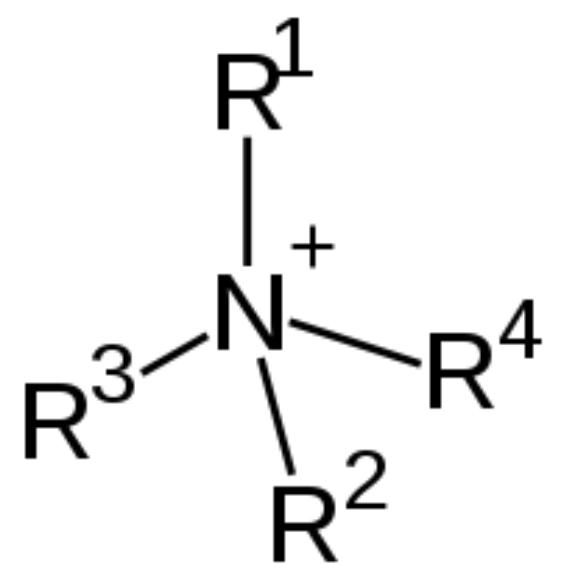

Figure 10: General QAS structure

QAS is a common alternative to heavy-metal groups. Research on these groups has shown antimicrobial ability against common gram negative and positive bacterium such as Staphylococcus aureus and Escherichia coli (27).

The topic of QAS as an additive to increase antimicrobial activity is also an area of focus for biomimetics. One commonly known chemical that is a naturally occurring QAS is chitosan. This is found on the exoskeletons of many shellfish and insects (28). The structure for chitosan is shown in Figure 11.

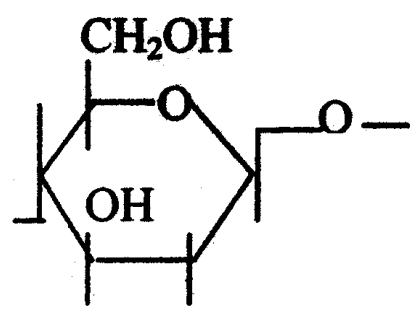

$\mathrm{NH}_{2}$

Figure 11: Structure for naturally occurring chitosan 
This initial state of chitosan does not have the desired effects when put through chemical synthesis. Therefore, the chitosan needs to be manipulated for synthesis use. Jia, et al., have described a way to quarternize the chitosan molecule so it can be used in chemical processes. This process is shown in Figure 12 , resulting in a positively charged $\mathrm{N}$ in the final state, $\mathrm{N}$-alkyl chitosan.

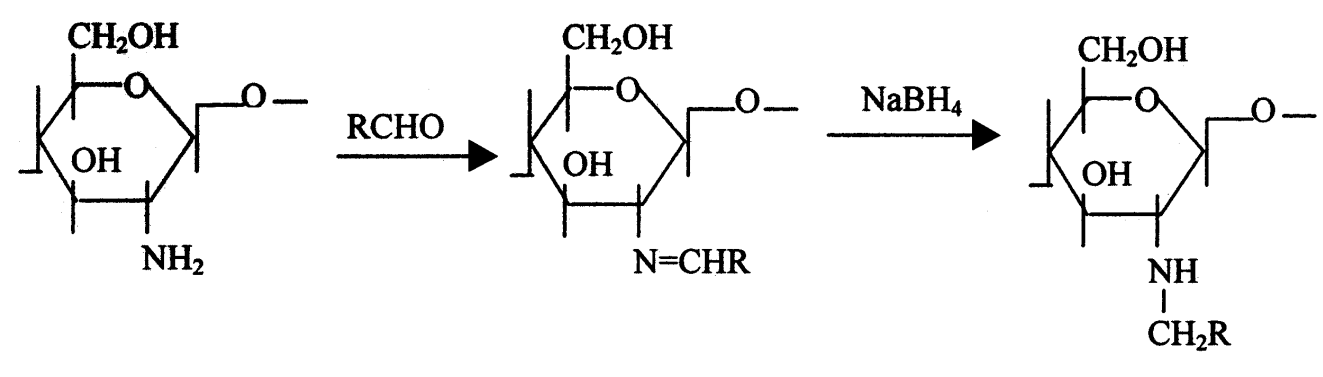

Chitosan

Schiff's base

$N$-alkyl chitosan

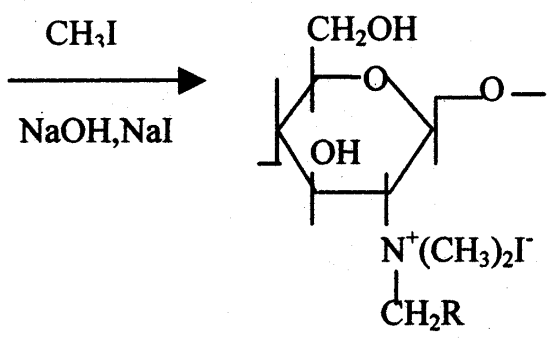

Figure 12: Quarternization process of chitosan

QAS groups also have the advantage of being incorporated into a silica based sol gel very easily; the QAS is incorporated after the initial hydrolysis reaction has begun. The QAS replaces one of the other organic functional groups on the end of the silanol molecules. Then, as two silanols react to form the final product, the QAS is incorporated into the matrix. (28).

\subsubsection{Cell Culture Studies}

Cell culture is the most common approach to test antimicrobial efficacy. This is done by growing a specified concentration of bacterium, then plating them on to 
a growth medium in a Petri dish. The plates are then incubated at $37^{\circ} \mathrm{C}$, body temperature, and observed after a specified incubation time. The incubation time allows colonies, or clusters, of bacteria to form. This is then measureable by counting the number of colonies formed.

\subsection{Tribological Analysis}

With thin films typically being less than $1 \mu \mathrm{m}$ thick, their ability to withstand normal wear and tear, and retain their desired function, is an issue. The study of wear and friction is more commonly known as tribology. The major types of wear that are studied by tribologists are abrasion, adhesion, cohesion, erosion, and corrosion.

There are many ways to test the durability using tribological approaches. The most common way to test thin films is by abrasion, often by reciprocating wear. This is done by repetitive wear across the surface by an abrasive agent. There are multiple configurations to complete this testing.

\subsubsection{Wear Testing}

The primary way to perform wear testing on a material is by the use of a tribometer. There are many variations of tribometers including reciprocating, pin on disk, etc (29). Different types of tribometers are shown in Figures 13-15. 


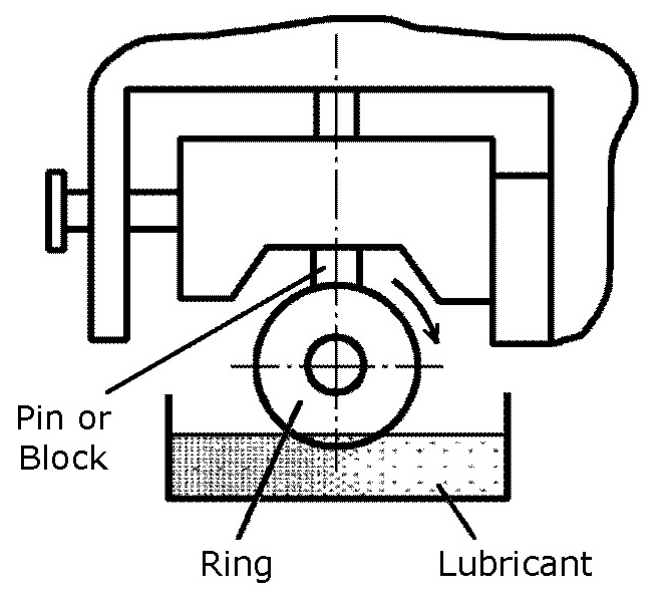

Figure 13: Schematic for pin-on-ring tribometer (29).

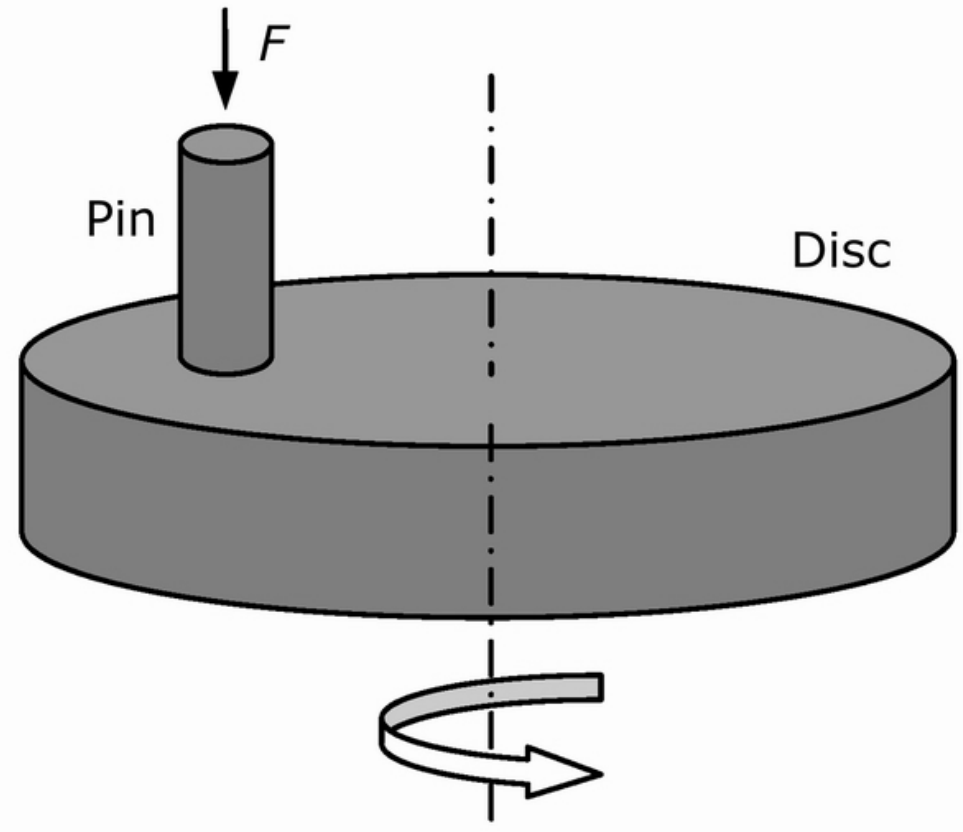

Figure 14: Schematic for pin-on-disk tribometer (29). 


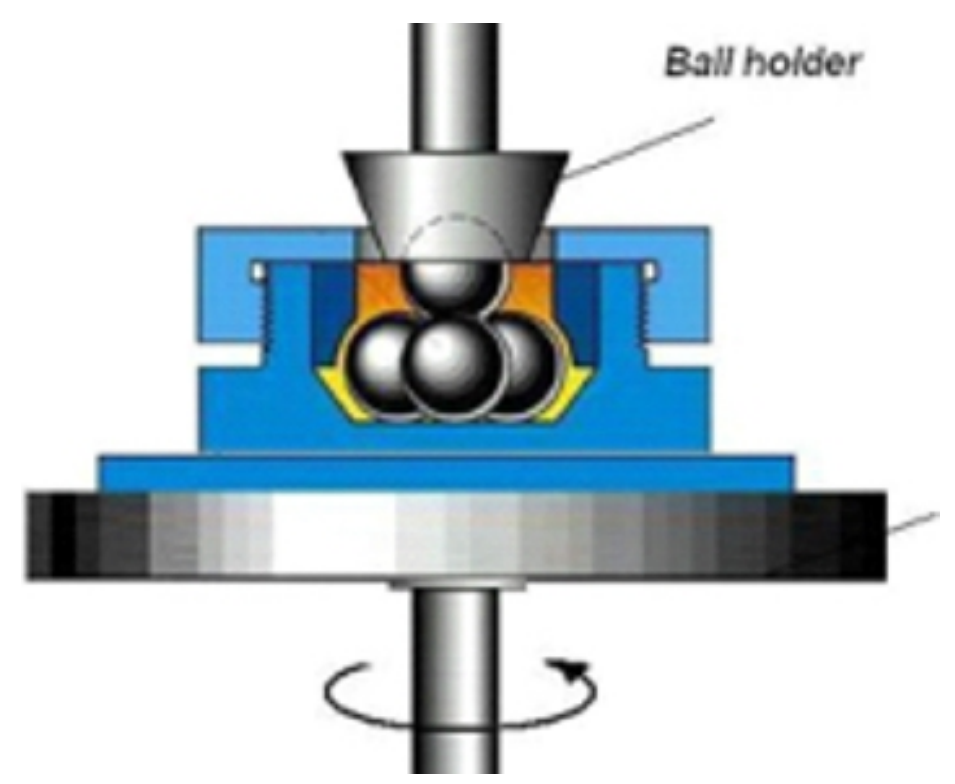

Figure 15: Schematic of four-ball tribometer (29).

Wear testing of materials is used to measure their degree of durability. The most common way to express the durability of a substance is the relative weight loss when subject to wear testing (30). This is not very easily accomplished with very small samples. Thin films are hard to measure weight loss because of how low their weight is initially. Thickness loss is another method to measure wear for thin films.

\subsection{Stylus Profilometry}

Profilometers use a small stylus that drags over the surface. This stylus is connected to a transducer that produces an electrical signal that is proportional to the displacement that is experienced by the tip of the stylus. This signal is then amplified and sent to a chart recorder that then displays a scaled view of the actual profile (30). A schematic of this setup is seen in Figure 16. 


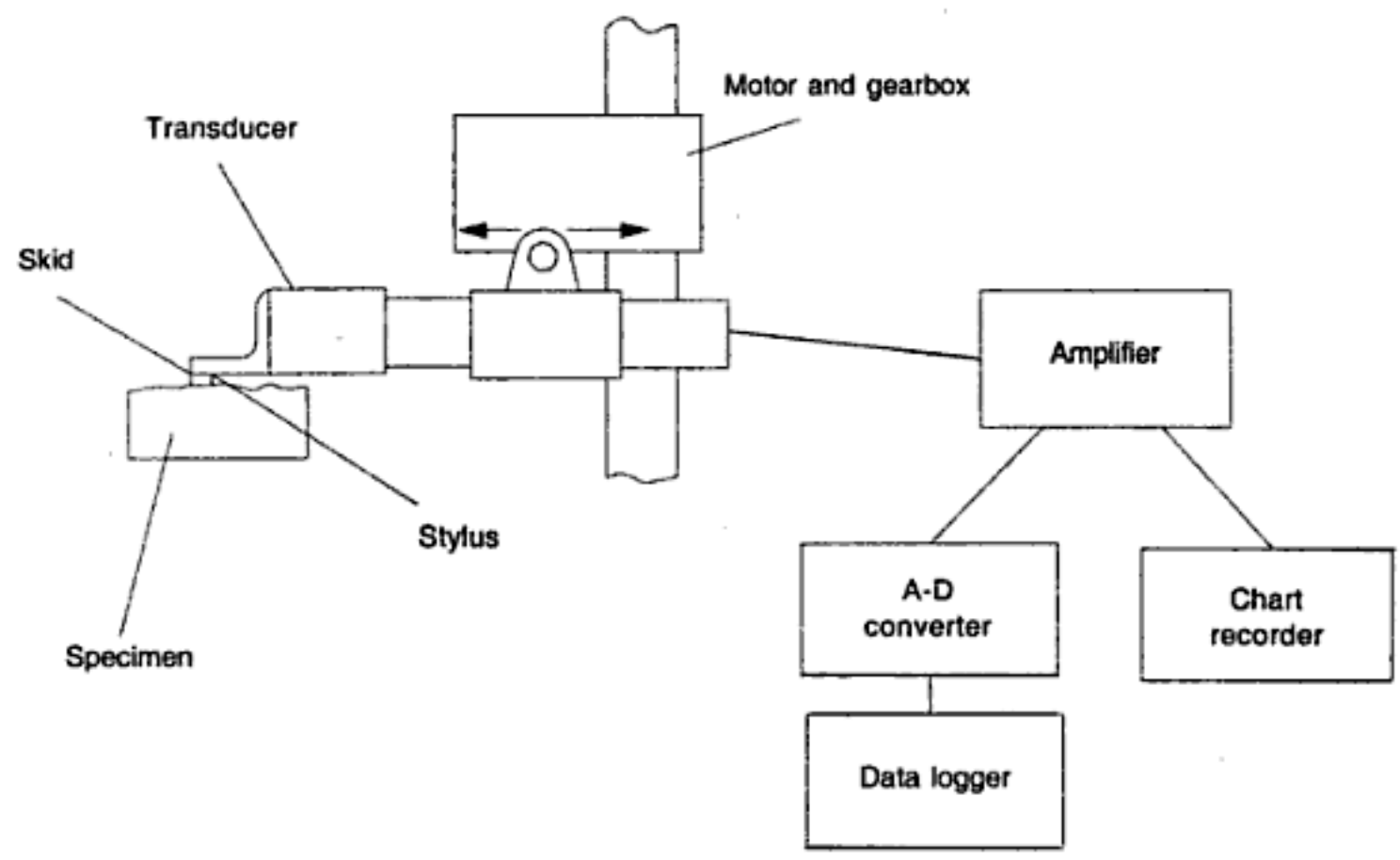

Figure 16: General schematic for stylus profilometer (30)

Films are considered "thin films" based on their thickness, nanometer to micrometer range. Profilometry can be used to determine initial coating thickness as well as coating thickness as a function of wear. This technique is also useful to determine surface roughness. Surface roughness is important when looking at hydrophobic surfaces. This enables the water to sit on top of a small amount of the surface rather than to lie across a large amount.

\subsection{EXPERIMENTAL PROCEDURES}

This section will include all procedures that were followed when creating these coatings in the laboratory. It will also cover analysis techniques that were used.

\subsection{Sol gel processing}

Sol gel processing is a mild chemical processing approach. This makes it ideal for laboratory applications. All chemicals needed for processing are readily 
available from standard laboratory suppliers. However, high purity reactants are needed, so this could increase start up cost.

For this research, all processing was done batch-wise in $25 \mathrm{~g}$ batches. This silica sol gel process is also convenient for processing because it can be treated as a one-pot co-condensation. This enabled quick processing times and ease of variation. Larger batches were not desirable because it would generate more chemical waste.

As mentioned previously, the starting alkoxide precursor is TEOS (Acros Organics). Other chemicals used to create these coatings are $\mathrm{HCl}$, water (deionized), and an alcohol to act as a diluent; typically ethanol. These are common chemicals, but high purity grades are needed, so that increases the cost of production.

The first step in this process is to start the initial hydrolysis reaction; combining TEOS and water does this. The water is added in two parts; one that is $100 \%$ deionized water and a second part that is a solution of $3.7 \mathrm{wt} \% \mathrm{HCl}$ in water. This is the catalyst for the reaction. After 1.25 hours of mixing to ensure a homogeneous mixture, it is then diluted with ethanol. These four starting materials were mixed in varying ratios of TEOS: $\mathrm{H}_{2} \mathrm{O}: \mathrm{HCl}: \mathrm{EtOH}$ of $1: 4: 0.01: 10$ to $1: 6: 0.01: 20$, depending on the particular sample formulation. After ethanol is added the sol was left to mix for a minimum time of three hours aging before it was coated on to substrates. All mixing was done under constant stirring. It should be noted that this is for a silica sol gel with no antimicrobial properties. When antimicrobial agents are added they are part of the molar ratio of TEOS. Therefore, the ratio of TEOS for the entire mixture was then broken into an internal ratio of TEOS:QAS; this value was 0.8:0.2 to 0.95:0.05. The ratio is so high because with more QAS added it takes away from the hydrophobic properties. 
An alternative mix procedure was explored briefly (31). This procedure consisted of mixing ethanol, water, and the acid catalyst until complete dissolution. Then the TEOS/QAS was added over a ten-minute period while stirring continuously. This resulted in a less homogeneous mixture than the original mix procedure. Therefore, this procedure was eliminated.

Coatings were initially diluted with an ethanol solution. Since ethanol is so expensive in higher purities, the formulation was modified to use methanol to see if there were any noticeable changes. After trials with three different formulations, there was no noticeable difference between the two diluents, so from then on all coatings were made with methanol.

\subsection{Substrate deposition}

Dip coating was the technique used in this research to coat the sol on to a substrate. This is an advantageous technique because it can be done rather quickly. Also, since the sol is already mixed in a single container, it is convenient to dip the substrate into the sol once a proper aging period has passed.

The substrate used for this research was glass microscope slides $(75 \mathrm{~mm} \times 25$ $\mathrm{mm} \times 1 \mathrm{~mm}$ by Fischer Scientific). A dip-coating machine was used to dip and withdraw the substrates in and out of the sol at a constant speed. The speed for this research was $200 \mathrm{~mm} / \mathrm{min}$. Before slides were coating they were wiped clean with a lint free cloth. Extra caution was taken to ensure that no contaminants were introduced into the sol, whether it was inside the mixing container or after it has been coated on to the substrate. After the slides were coated, they were left to dry in ambient conditions overnight before thermal treatment. 


\subsection{Drying}

Drying temperature and duration was determined initally by observing decomposition temperatures using thermogravimetric analysis (TGA). TGA scans were done with dried sol samples that were not coated on to a substrate. The scans were done in a ramped mode with a constant temperature increase of $10^{\circ} \mathrm{C} / \mathrm{min}$. Scans were also done at a constant temperature to determine how long the materials could sustain. Decomposition scans were also done with QAS samples to determine the maximum temperature it could handle before functionality is lost. It was determined that the coating is able to withstand a thermal treatment of $175^{\circ} \mathrm{C}$ for a three-hour period.

\subsection{Contact Angle}

Goniometers are devices that are used to measure angles. There are specific goniometers made for measuring water contact angle, such as the piece of equipment produced by Ramé-Hart, shown in Figure 17 (32). For the purposes of this research, a rudimentary goniometer was used. 


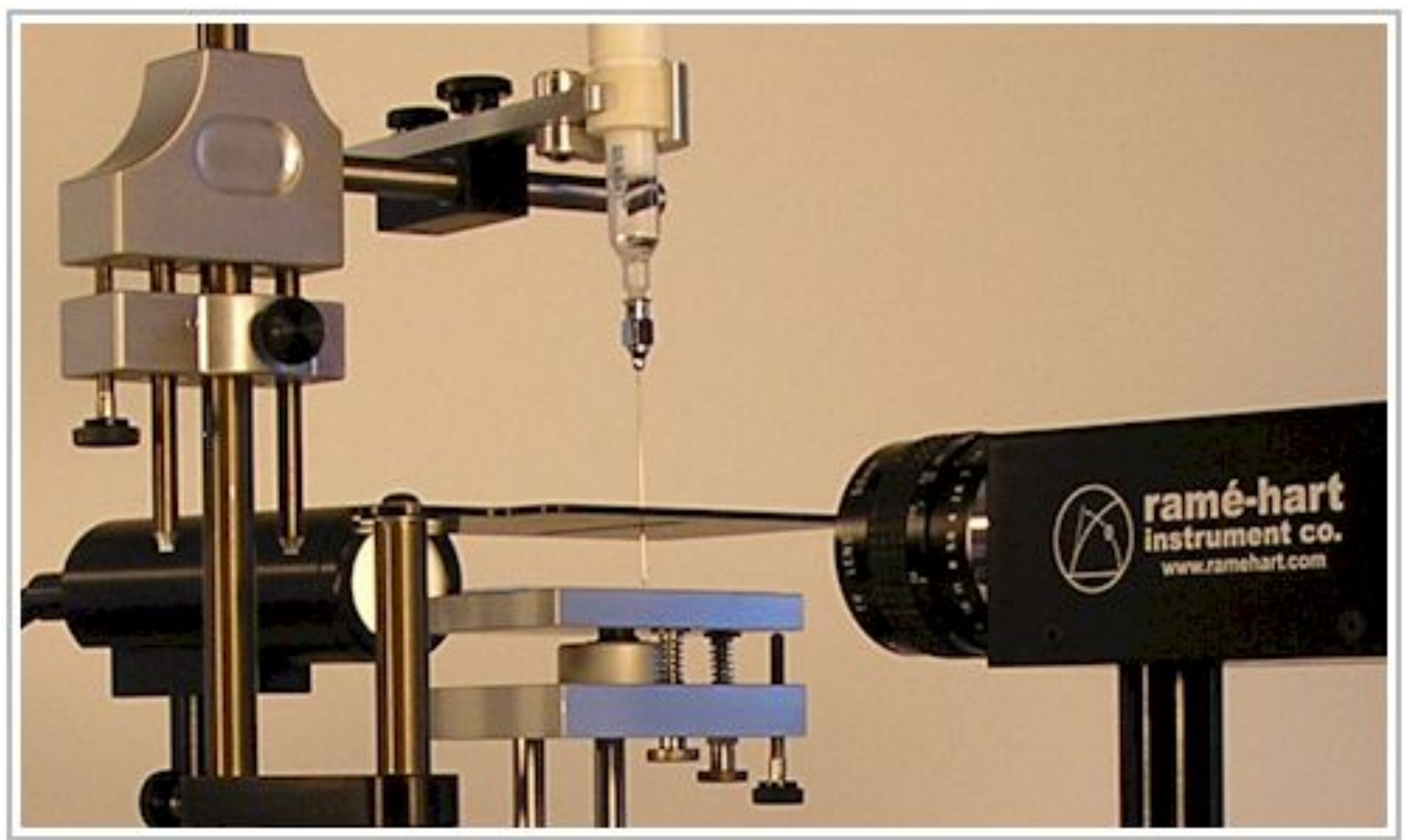

Figure 17: Ramé-Hart goniometer (32)

The first step for starting a contact angle measurement is to clean the sample. An alcohol-based glass cleaning solution was used with a lint-free cloth to thoroughly clean the sample surface. Deionized water is placed on to the sample surface in 1-2uL drops from a syringe. Five drops are placed on the surface; this creates an average contact angle value for the surface to account for variations. The goniometer consists of a microscope stage for the samples to sit on. The samples are then placed in front of a USB microscope connected to a computer to produce a live feed of the images. A still image is captured from the microscope. This image is then post-processed to determine the water contact angle. Images are processed in ImageJ, with contact angle analysis done by a NIH plug-in "Drop Analysis".

\subsection{Thickness}

A stylus profilometer, Veeco Dektak 150, was used for thickness measurements. Thickness measurements were taken after each slide was produced and during 
each time step of the wear testing procedure. To measure the thickness, a razor blade was used to remove a thin strip of the coating from the substrate. Extra caution was taken to not scratch into the substrate, as this would produce a false value for the coating thickness. The stylus profilometer was then set to run a $1000 \mu \mathrm{m}$ sampling length. This was orientated so the scratch was near the middle of the sampling length, with the direction of the scan perpendicular to the scratch. This allowed the thickness to be measured as an absolute value of the difference in heights.

\subsection{Wear Testing}

Wear testing was done using a lab-built reciprocating wear tribometer. This tribometer was used to wear the samples at a constant frequency with a known load.

The device consisted of a rectangular bath as the base. This is filled with a slurry of $300 \mathrm{~nm}$ diameter alumina particles dissolved in deionized water. The center of the base has a notch cut out for a glass microscope slide to fit. This ensures that the sample is in the same location every time. The reciprocating arm moves in the $y$-direction, while the load is variable in the z-direction so it can be raised and lowered in and out of the base to position the sample for testing.

The load that is used is a metal wheel that exerts a known force of $4.7 \mathrm{mN}$ and has a diameter of $38 \mathrm{~mm}$. The outer diameter of this wheel is covered with a cloth pad. This is the surface that will be in contact with the sample during wear. Under operating conditions, this cloth is immersed in the alumina slurry, therefore the alumina is abrasive and will wear the surface of the samples. Each test consists of 100 wear cycles across the sample; this is all controlled by a Zaber stepper motor (NM34A200).

\subsection{Cell Culture}

Cell culture studies were preformed with $E$. coli as the bacteria of target. These 
studies were preformed in a hood and sterile environment to ensure no contaminations.

The first step of the cell culture process was to make a growth medium to put into the petri plates. This was made in $500 \mathrm{~mL}$ batches. After this was made it had to be sterilized in an oven for 4 hours. All work with the petri plates from this point on was done under a hood and under sterilized conditions. Once that process was complete it was poured into petri dishes. One batch was capable of making 15 petri plates for culturing. The growth medium was poured into the dishes and they were left to solidify overnight.

Then, it was time to prepare the bacteria. E. coli was taken from a concentrated solution and diluted to a concentration of $10^{6} \mathrm{cells} / \mathrm{mL}$. The diluent for this procedure is a phosphate buffered saline (PBS) solution. The amount of $\mathrm{mL}$ of bacteria needed is dependent on how many sample dishes there will be. For this research, samples were cultured in batches of six; two control samples (no coating), two TEOS only coatings, and two TEOS and QAS samples. Each sample was placed in a small petri dish then covered with $2 \mathrm{~mL}$ of bacteria solution. These samples were then placed in a heater $\left(37^{\circ} \mathrm{C}\right)$ that also had a rotating base. This enabled the samples to incubate at body temperature and have the solution mixing with the samples.

$0.5 \mu \mathrm{L}$ samples were taken at specific time intervals; $1 \mathrm{~min}, 10 \mathrm{~min}, 30 \mathrm{~min}, 60$ $\min , 12 \mathrm{hr}, 24 \mathrm{hr}, 48 \mathrm{hr}$. These samples were then dropped into the center of a growth medium petri plate; swirling the liquid over the entire exposed area then plates the sample. These samples were then placed into another incubator for 24 hours. After the incubation period, the plates were taken out and colonies forming units (CFUs) were counted. 


\subsection{RESULTS}

\subsection{Contact Angle Analysis}

The main objective of a hydrophobic coating is to increase the contact angle. Using the lab-built goniometer and ImageJ for post processing of photographs, the contact angles of sample surfaces was determined. Figure 18 shows an example of the 5 drops of water laid on to the coating surface. 5 drops were used so that an average contact angle can be used to account for any variation in the coating. 


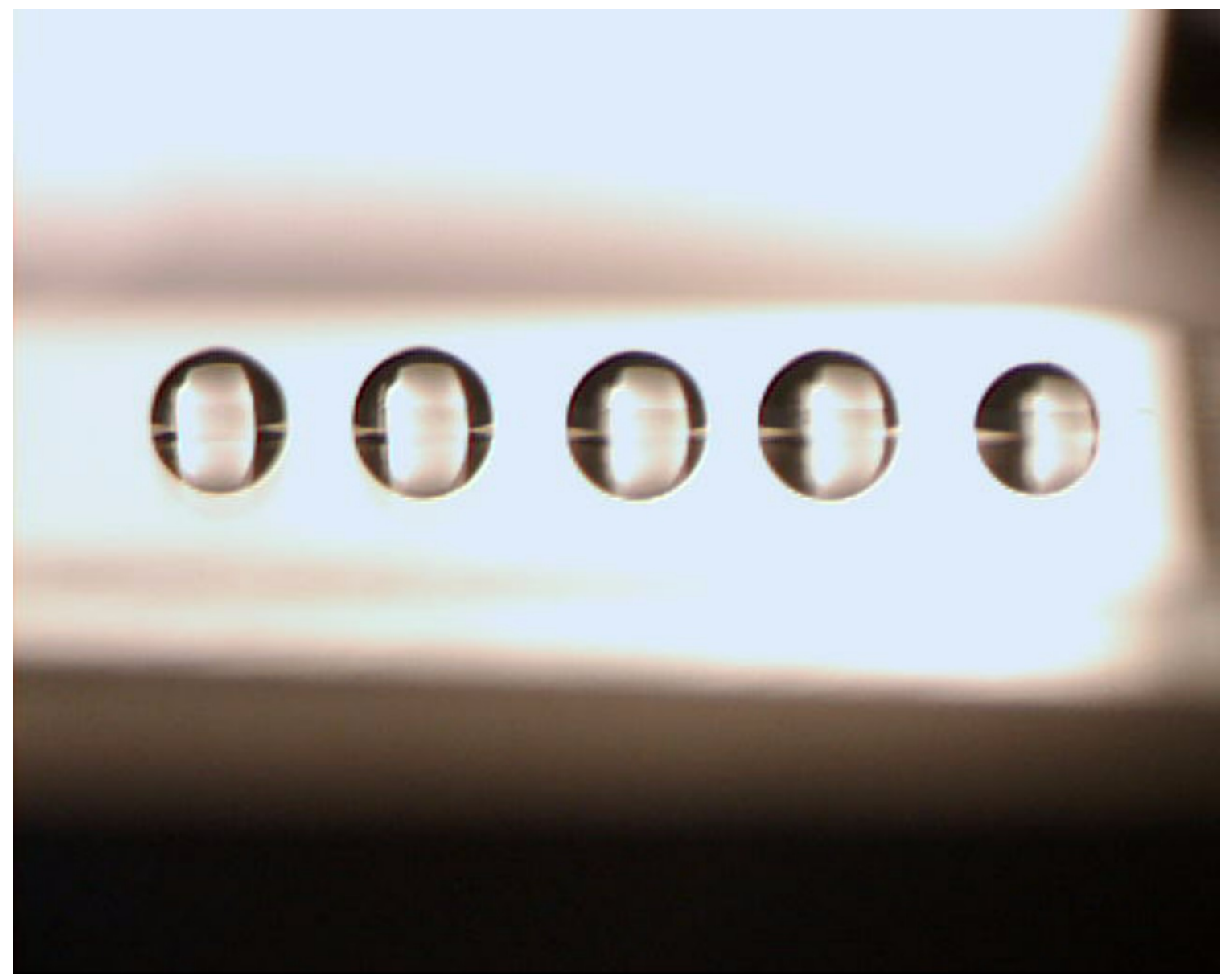

Figure 18: Example of sample contact angle analysis photo.

Each sample had a photo taken before, during, and after all wear testing. This was to measure the contact angle on the surface and throughout the bulk of the coating.

Changes in formulation were controlled one variable at a time to easily determine which factors are important. An example of this point, as mentioned previously, is the switch from ethanol to methanol as the diluent. Table 1 shows the two average surface contact angle values for these two formulations, each with five samples. The minor variations in contact angle ensured that the diluent change had a negligible effect. 
Table 1: Surface contact angle comparison

\begin{tabular}{|c|c|}
\hline Ethanol & Methanol \\
\hline 83.8 & 92.2 \\
\hline 84.2 & 90.4 \\
\hline 85.1 & 89.3 \\
\hline 90.1 & 88.2 \\
\hline 86.1 & 84.7 \\
\hline
\end{tabular}

Surface contact angle was also measured as a function of coating thickness, which was varied by changing the withdrawal speed. The results are shown in Table 2.

Table 2: Surface contact angle on samples of same formulation, coated at different withdrawal rates.

\begin{tabular}{|c|c|}
\hline $\begin{array}{c}\text { Surface } \\
\text { Contact } \\
\text { Angle } \\
\left({ }^{\circ}\right)\end{array}$ & $\begin{array}{c}\text { Withdrawal } \\
\text { Rate } \\
(\mathrm{mm} / \mathrm{min})\end{array}$ \\
\hline 91.5 & 200.0 \\
\hline 93.7 & 150.0 \\
\hline 85.3 & 100.0 \\
\hline 85.0 & 50.0 \\
\hline 86.7 & 25.0 \\
\hline
\end{tabular}

Coating thickness has a very little effect on the surface contact angle of a coating. The contact angle on the surface is important because this is the part of the coating that will be in contact with outside pieces first. When wear becomes an issue, then coating thickness will have a more pronounced effect. Figure 19 shows contact angle as a function of wear for two different formulations, the only difference being the amount of methanol added. 


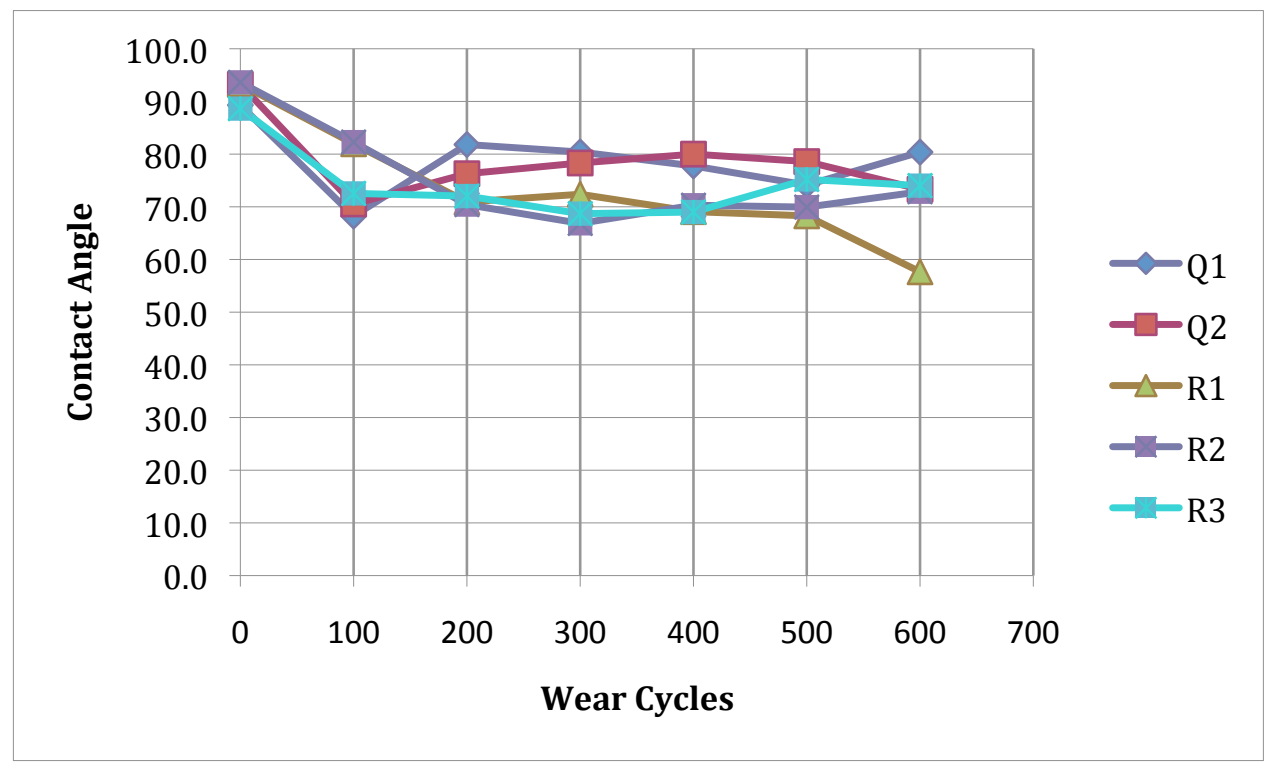

Figure 19: Contact angle as a function of wear

For the majority of the samples created for this research, the surface contact angle was near or at $90^{\circ}$. This puts these coatings near the threshold of being hydrophobic. Some samples made had surface contact angles approaching $105^{\circ}$.

\subsection{Wear Testing}

This was done using the lab build reciprocating wear tester. It was configured to wear samples in intervals of 50 cycles. Then, thickness and contact angle were measured between each run.

Initial coating thicknesses were seen as high as $800 \mathrm{~nm}$ and as low as $75 \mathrm{~nm}$ depending on formulation, aging, and withdrawal speed.

Table 3 shows typical thickness degradation with wear. Wear was typically stopped after the coating reached about $100 \mathrm{~nm}$. At that point it was extremely difficult to produce a scratch that was able to collect five points consistently. 
Table 3: Average coating thickness per wear cycle

\begin{tabular}{|c|c|c|c|}
\hline $\begin{array}{c}\text { Cycle } \\
\text { Number }\end{array}$ & $\begin{array}{c}\text { Wear } \\
\text { Cycles }\end{array}$ & $\begin{array}{c}\text { Average } \\
\text { Thickness } \\
(\mathrm{nm})\end{array}$ & $\begin{array}{c}\text { Thickness } \\
\text { Loss \% }\end{array}$ \\
\hline 0 & 0 & 528 & 0.0 \\
\hline 1 & 50 & 457 & 13.3 \\
\hline 2 & 100 & 419 & 20.6 \\
\hline 3 & 150 & 372 & 29.4 \\
\hline 4 & 200 & 317 & 40.0 \\
\hline 5 & 250 & 231 & 56.2 \\
\hline 6 & 300 & 159 & 69.9 \\
\hline 7 & 350 & 99 & 81.3 \\
\hline
\end{tabular}

With an $80 \%$ loss over 7 wear cycles, the coating is now rendered useless. At a reciprocating speed of $1 \mathrm{~Hz}$, the 7 cycles took about 12 minutes of total wear.

\subsection{Cell Culture Studies}

These studies were done to determine the viability of $E$. coli in the presence of a coating with antimicrobial properties. The amount of antimicrobial agent added into the sol was very small, so as not to compromise the other properties.

Figure 20 shows an example of Petri plates made from agar, ready for culturing. This is shown in the sterile hood. Figure 21 shows the shaker machine to keep the samples oscillating while heating. 


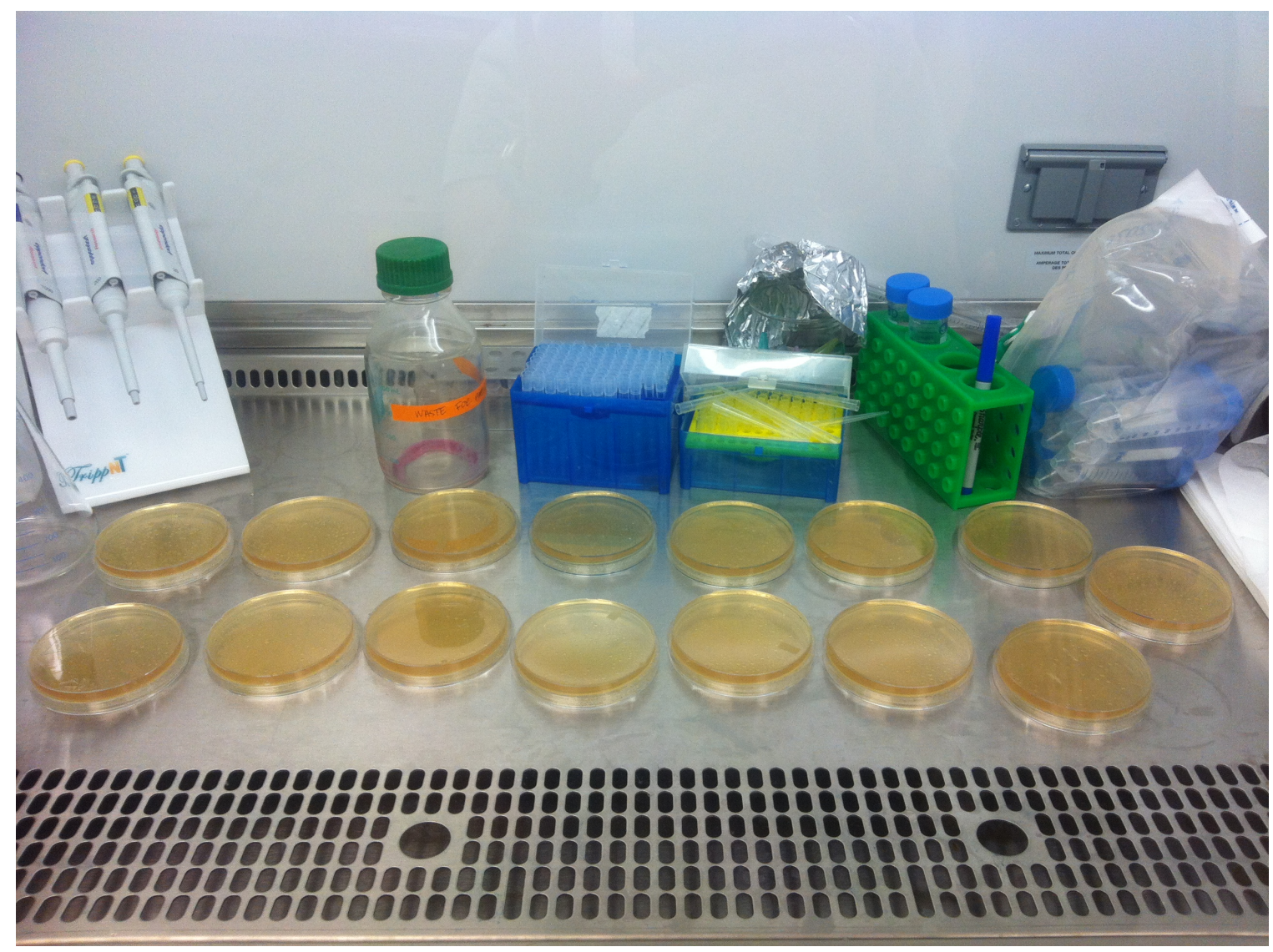

Figure 20: Sterile Petri plates 


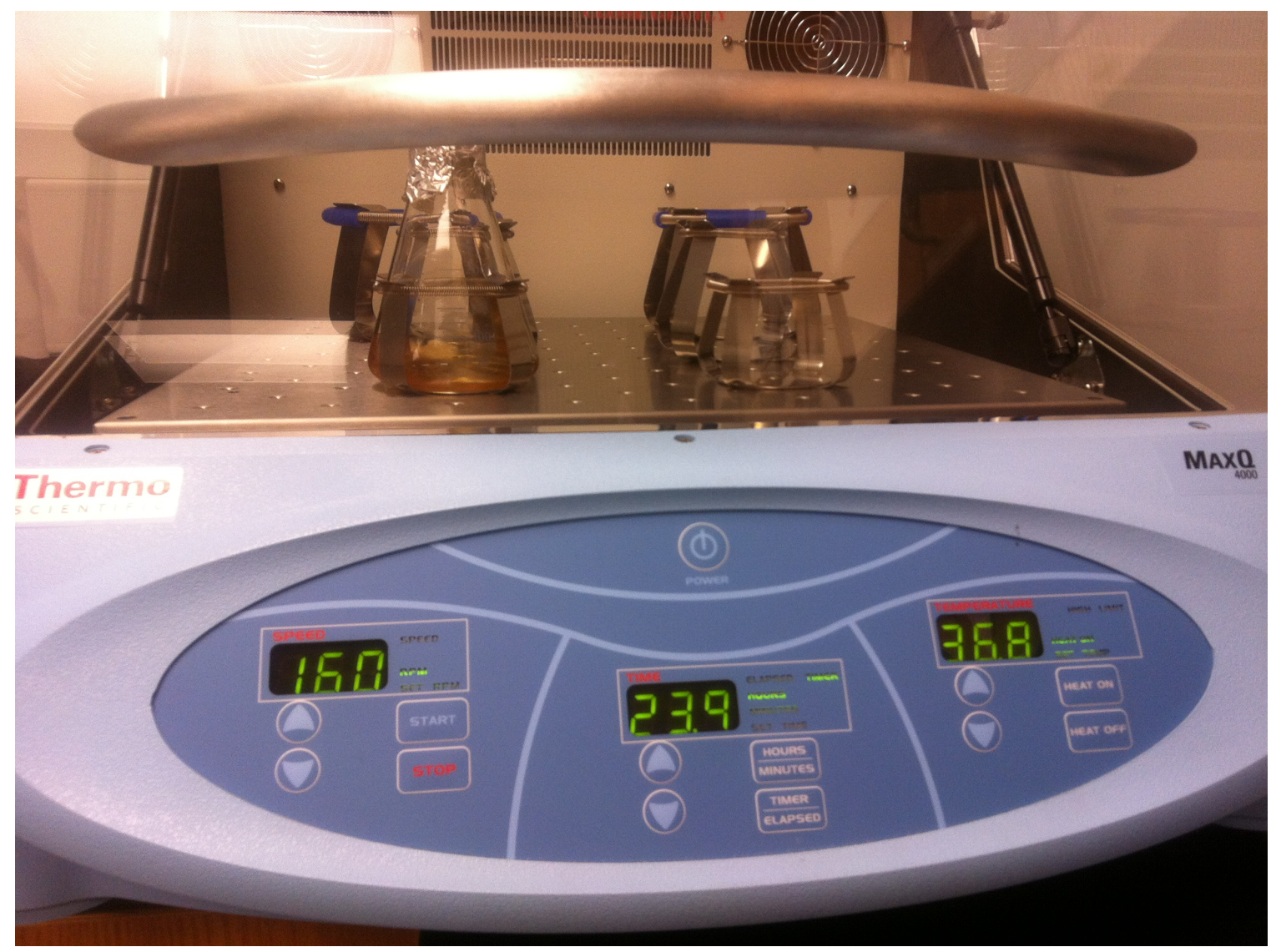

Figure 21: Heated shaker machine used for sample incubation before plating

Counting CFUs was the method used to determine the efficacy of the antimicrobial agent in the coating. Figure 22 shows four cultured Petri plates after incubation. The two plates on the bottom were from control samples. One control was a glass slide with no coating, bottom left, and the second was a glass slide with a TEOS only coating, bottom right. The two Petri plates on the top had QAS incorporated. The plate on the top right was a TEOS and QAS coating that had been worn, and the top left was an unworn TEOS/QAS coating. The bacteria are more prevalent in the control plates, and there are fewer CFUs in the QAS incorporated plates. 


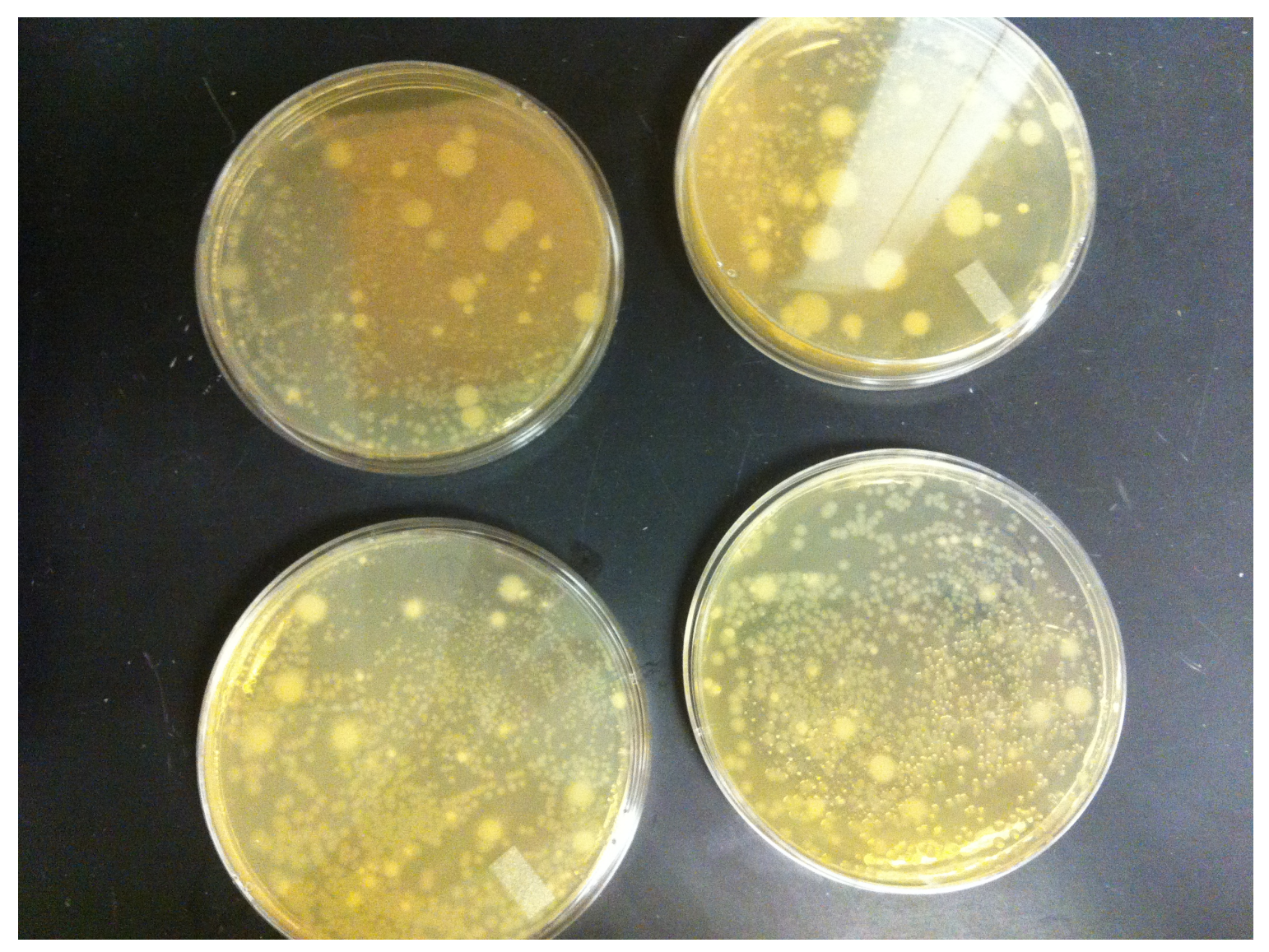

Figure 22: Cultured Petri plates

\subsection{Discussion and Conclusions}

Throughout this research I was able to create a thin film coating that was hydrophobic, durable, and antimicrobial. A silica sol gel process with the incorporation of an antimicrobial agent did this during the hydrolysis reaction.

The coating did possess antimicrobial properties, but the degree was not very high. This could be due to the low amount of QAS that was incorporated into the coating. More could be added, but then there is a trade-off for the hydrophobicity. This coating was able to achieve its the main functions. 


\subsection{Future Work}

I think that surface templating should be explored for this application. This would make the surface superhydrophobic. Also, surfactant templating would be advantageous to create a more hydrophobic environment within the bulk of the coating. 


\subsection{References}

1. Mitzi, David B., Thin-Film Deposition of Organic-Inorganic Hybrid Materials. Chem. Mater. 2001, 13, 3282-3298.

2. Tamaki, J., Naruo, C., Yamamoto, Y., Matsuoka, M., Sensing properties to dilute chlorine gas of indium oxide based thin film sensors prepared by electron beam evaporation. Sensors and Actuators B: Chemical. 15 March 2002, 83, 1-3, 190-194.

3. Takeda, S., Suzuki, S., Odaka, H., Hosono, H., Photocatalytic $\mathrm{TiO}_{2}$ thinfilm deposited on to glass by DC magnetron sputtering. Thin Solid Films. 30 July 2001, 392, 2, 338-344.

4. Watanabe, K., Udagawa, H., Drag reduction of non-newtonian fluids in a circular pipe with a highly water-repellent wall. AIChE Journal. February 2001, 47, 2, 256-262.

5. Hench, L. L., West, J. K., The Sol-Gel Process. Chem. Rev. 1990, 90, 33-72.

6. Wright, J., Sommerdijk, N., Sol-gel materials: chemistry and applications. 2001, CRC press.

7. Wen, J., Wilkes, G. L., Organic/Inorganic Hybrid Network Materials by the Sol-Gel Approach. Chem. Mater. 1996, 8, 1667-1681.

8. Aelion, R., Loebel, A., Eirich, F., Hydrolysis of Ethyl Silicate. Journal of the American Chemical Society, Dec 1950, 72, 5705-5712

9. Rao, A. V., Haranath, D., Effect of methyltrimethoxysilane as a systhesis component on the hydrophobicity and some physical properties of silica aerogels. Microporous and Mesoporous Materials. 1999, 30. 2-3, 267 - 273.

10. Yokogawa, H., Yokoyama, M., Hydrophobic silica aerogels. Journal of Non-Crystalline Solids. 1995, 186, 23-29.

11. Heley, J. R., Jackson, D., James, P. F., Fine low density silica powders prepared by supercritical drying of gels derived from silicon tetrachloride. Journal of Non-Crystalline Solids. 1995, 186, 30-36. 
12. Hegde, N. D., Rao, A. V., Organic modification of TEOS based silica aerogels using hexadecyltrimethoxysilane as a hydrophobic reagent. Applied Surface Science. 2006, 253, 1566-1572.

13. Tslonsky, M., Gun, G., Glezer, V., Lev, O., Sol-Gel-Derived CermaicCarbon Composite Electrodes: Introduction and Scope of Applications. Journal of Analytical Chemistry. 1994, 66, 10, 1747-1753.

14. Suneel, S. D. Nanotechnology. 3.1 Wet Chemical Synthesis of nanomaterials (sol-gel process).

http://www.gitam.edu/eresource/nano/nanotechnology/bottamup\%20ap p.htm

15. Van Hardeveld, R. M., Gunter, P. L. J., van IJzendoorn, L. J., Wieldraaijer, W., Kuipers, E. W., Niemantsverdriet, J. W., Deposition of inorganic salts from solution on flat substrates by spin-coating: theory, quantification and application to model catalysts. Applied Surface Science. 1995, 84, 339-346.

16. Brinker, C. J., Frye, G. C., Hurd, A. J., Ashley, C. S., Fundamentals of sol-gel dip-coating. Thin Solid Films. 1991, 201, 97-108.

17. Schottner, G., Hybrid Sol-Gel Derived Polymers: Applications of Multifunctional Materials. Chem. Mater. 2001, 13, 3422-3435.

18. Kwok, D. Y., Neumann, A. W., Contact angle measurement and contact angle interpretation. Advances in Colloid and Interface Science. 1999, 81, 167-249.

19. Ramé-Hart. Information on contact angle. 2012. http://www.ramehart.com/contactangle.htm

20. Lam, C. N. C., Wu, R., Li, D., Hair, M. L., Neumann, A. W., Study of the advancing and receding contact angles: liquid sorption as a cause of contact angle hysteresis. Advances in Colloid and Interface Science. 2002, 96, 169 - 191.

21. Miwa, M., Nakajima, A., Fujishima, A., Hashimoto, K., Wantanabe, T., Effects of the Surface Roughness on Sliding Angle of Water Droplets on Superhydrophobic Surfaces. Langmuir, 2000, 165754 - 5760. 
22. Ramé-Hart. Glossary of Surface Science Terms. 2012. http://www.ramehart.com/glossary.htm

23. Ma, M., Hill, R., Superhydrophobic Surface,s. Current Opinions in Colloid \& Interface Science II. 2006, 4, 193 - 202.

24. Rao, A. P., Rao, A. V., Pajonk, G. M., Hydrophobic and physical properties of the ambient pressure dried silica aerogels with sodium silicate precursor using various surface modification agents. Applied Surface Science. 2007, 253, 6032 - 6040.

25. Barberoglou, M., Tzanetakis, P., Fotakis, C., Stratakis, E., Spanakis, E., Zorba, V., Rhizopoulou, S., Anastasiadis, S., Laser structuring of water-repellent biomimetic surfaces. SPIE Newsroom. 19 January 2009.

26. Patankar, N. A., On the Modeling of Hydrophobic Contact Angles on Rough Surfaces. Langmuir, 2003, 19, 1249 - 1253.

27. Marini, M., Bondi, M., Iseppi, R., Toselli, M., Pilati, F., Preparation and antibacterial activity of hybrid materials containing quarternary ammonium salts via sol-gel process. European Polymer Journal. 2007, 43, $3621-3628$.

28. Jia, Z., Shen, D., Xu, W., Synthesis and antibacterial activities of quaternary ammonium salt of chitosan. Carbohydrate Research. 2001, 333, $1-6$.

29. Tribology Laboratory Belgrade. Equipment. http://tribolab.mas.bg.ac.rs/english/equipment.htm

30. Sahoo, P., Engineering Tribology. PHI Learning Pvt, Ltd. Aug 1, 2005.

31. Izquierdo-Barba, I., Vallet-Regi, M., Kupferschmidt, N., Terasaki, O., Schmidtchen, A., Malmsten, M., Incorporation of antimicrobial compounds in mesopourous silica film monolith. Biomaterials, 2009, 30, 29, $5729-5736$.

32. Ramé-Hart. Contact angle goniometers and tensiometers. 2012. http://www.ramehart.com/goniometer.htm 


\title{
8.0 Curriculum Vitae
}

\section{Education}

\author{
M.S. Mechanical Engineering \\ Expected August 2012 \\ West Virginia University \\ B.S. Chemical Engineering \\ May 2010 \\ West Virginia University
}

\section{Research Experience}

\section{WVU Department of Mechanical and Aerospace Engineering}

Graduate Research Assistant in materials characterization laboratory.

- Coatings are silica-based matrix with quaternary ammonium salts incorporated to achieve antimicrobial properties.

- The mixture is coated on to a glass substrate, and then subjected to durability testing and cell culture studies

- Help teach freshman introduction to nanotechnology lab.

\section{Alliant Techsystems, Inc.}

Internship in the Propellant Chemistry Department.

- Conducted preliminary research and experiments on how to efficiently stop a rocket motor propellant cure reaction.

- Created and updated various databases.

- Experience reading technical papers and technical drawings. Exposed to the challenges that engineers are faced with everyday.

\section{NASA West Virginia Space Grant Consortium Undergraduate Research Fellow: \\ "Development of a Novel '3 in 1' Drug Delivery System"}

- Novel nanocoating with three different drugs incorporated into one coating.

- Each drug would have its own specified release profile that is triggered by certain situations.

- The three release profiles are a constant release, burst release, and prolonged release. 
- Cell culture studies were conducted.

\section{WVNano SURE Program - WVU School of Medicine: Department of Orthopaedics}

- Development of a nanocoating made of weak polyelectrolytes.

- This coating can be loaded with various antibiotics.

- Intended use to coat implants to reduce infections.

\section{Publications}

- Jiang, Bingbing, Elizabeth DeFusco, and Bingyun Li. "Polypeptide Multilayer Film Co-Delivers Oppositely-Charged Drug Molecules in Sustained Manners." Biomacromolecules 11.12 (2010): 3630-637. Print.

- Kessman, Aaron J., Elizabeth E. DeFusco, Andrew W. Hoover, Konstantinos A. Sierros, and Darran R. Cairns. "Structural, Mechanical, and Tribological Properties of Fluorinated Mesoporous Silica Films: Effect of Functional Moiety and Surfactant Template Concentrations." Thin Solid Films (2012). 520, 11, 3896-3903

- Kessman, Aaron J., Elizabeth E. DeFusco, Andrew W. Hoover, Konstantinos A. Sierros, and Darran R. Cairns. "Sustained Protection for Transparent Electrodes in Touch Panels and Smart Windows: Template Assisted Encapsulation of Fluorinated Silanes in Sol-Gel Silica Films for Sustained Hydrophobic-Oleophobic Functionality". 2011 MRS Fall Meeting 